OPEN ACCESS

Edited by:

Maurizio Acampa,

Siena University Hospital, Italy

Reviewed by:

Elisabeth Lambert,

Swinburne University of Technology,

Australia

Junbao Du,

Peking University First Hospital, China

*Correspondence:

Victoria E. Claydon victoria_claydon@sfu.ca

Specialty section:

This article was submitted to

Autonomic Neuroscience,

a section of the journal

Frontiers in Neuroscience

Received: 13 August 2019

Accepted: 22 October 2019

Published: 12 November 2019

Citation:

Coupal KE, Heeney ND, Hockin $B C D$, Ronsley R, Armstrong $K$,

Sanatani S and Claydon VE (2019)

Pubertal Hormonal Changes and the Autonomic Nervous System: Potential Role in Pediatric Orthostatic Intolerance. Front. Neurosci. 13:1197. doi: 10.3389/fnins.2019.01197

\section{Pubertal Hormonal Changes and the Autonomic Nervous System: Potential Role in Pediatric Orthostatic Intolerance}

\author{
Kassandra E. Coupal'1, Natalie D. Heeney', Brooke C. D. Hockin'1, Rebecca Ronsley², \\ Kathryn Armstrong ${ }^{3}$, Shubhayan Sanatani ${ }^{3}$ and Victoria E. Claydon ${ }^{1 *}$ \\ ${ }^{1}$ Department of Biomedical Physiology and Kinesiology, Simon Fraser University, Burnaby, BC, Canada, ${ }^{2}$ Department \\ of Pediatrics, BC Children's Hospital, Vancouver, BC, Canada, ${ }^{3}$ Children's Heart Centre, BC Children's Hospital, Vancouver, \\ $B C$, Canada
}

Puberty is initiated by hormonal changes in the adolescent body that trigger physical and behavioral changes to reach adult maturation. As these changes occur, some adolescents experience concerning pubertal symptoms that are associated with dysfunction of the autonomic nervous system (ANS). Vasovagal syncope (WS) and Postural Orthostatic Tachycardia Syndrome (POTS) are common disorders of the ANS associated with puberty that are related to orthostatic intolerance and share similar symptoms. Compared to young males, young females have decreased orthostatic tolerance and a higher incidence of WS and POTS. As puberty is linked to changes in specific sex and non-sex hormones, and hormonal therapy sometimes improves orthostatic symptoms in female WS patients, it is possible that pubertal hormones play a role in the increased susceptibility of young females to autonomic dysfunction. The purpose of this paper is to review the key hormonal changes associated with female puberty, their effects on the ANS, and their potential role in predisposing some adolescent females to cardiovascular autonomic dysfunctions such as WS and POTS. Increases in pubertal hormones such as estrogen, thyroid hormones, growth hormone, insulin, and insulin-like growth factor-1 promote vasodilatation and decrease blood volume. This may be exacerbated by higher levels of progesterone, which suppresses catecholamine secretion and sympathetic outflow. Abnormal heart rate increases in POTS patients may be exacerbated by pubertal increases in leptin, insulin, and thyroid hormones acting to increase sympathetic nervous system activity and/or catecholamine levels. Given the coincidental timing of female pubertal hormone surges and adolescent onset of WS and POTS in young women, coupled with the known roles of these hormones in modulating cardiovascular homeostasis, it is likely that female pubertal hormones play a role in predisposing females to WS and POTS during puberty. Further research is necessary to confirm the effects of female pubertal hormones on autonomic function, and their role in pubertal autonomic disorders such as WS and POTS, in order to inform the treatment and management of these debilitating disorders.

\footnotetext{
Keywords: puberty, syncope, orthostatic intolerance, vasovagal, POTS
} 


\section{INTRODUCTION}

\section{Puberty Is Associated With Orthostatic Intolerance}

Puberty is a period of adolescence in which a child undergoes rapid changes that affect physical and mental functioning in order to reach adult maturation. During this time many adolescents experience substantial fatigue, mood swings, and stress (Larson et al., 1980). These symptoms of puberty are well-known and not generally worrisome (Larson et al., 1980; Wheeler, 1991; Viner and Christie, 2005; Table 1). However, other physical symptoms can occur at the onset of puberty that reflect autonomic nervous system (ANS) dysfunction, compromising the homeostatic regulation of basic bodily functions (Palma et al., 2017; Table 2). For example, puberty is associated with an increased incidence of syncope (fainting: transient loss of consciousness and postural tone) or presyncope (near-fainting), particularly in females (Walsh, 2001).

Syncope and presyncope are common across the lifespan, but have a particularly high incidence in adolescents, with a peak age of onset during puberty at age $\sim 10-15$ years (Figure 1); approximately 1 in three adolescents with syncope experience recurrent and severe episodes (de Jong-de Vos van Steenwijk et al., 1995; Driscoll et al., 1997; McLeod, 2003; Kenny et al., 2010; Kanjwal and Calkins, 2015). However,

TABLE 1 | Typical features of puberty.

\begin{tabular}{|c|c|}
\hline Physical changes & Mental/Emotional changes \\
\hline Breast, penis, testicle development & $\begin{array}{l}\text { Mood swings - aggression, emotional } \\
\text { surges, bouts of crying }\end{array}$ \\
\hline Body hair - appearance in armpits and & Changes in sleep patterns and fatigue \\
\hline
\end{tabular}

pubic area

Growth spurts and weight gain

Menstruation and menstrual

symptoms - nausea, cramps, bloating,

diarrhea, aching in upper thighs,

headache, backache, stomach ache

Widening of the hips/shoulders

Increased subcutaneous fat

distribution/muscle development

Typical physical and mental/emotional changes are shown. Adapted from Larson et al. (1980), Wheeler (1991), and Viner and Christie (2005).

TABLE 2 | Concerning features of puberty.

\section{Physical changes}

Dizziness and syncope upon standing

Exercise intolerance

Sweating abnormalities - hyperhidrosis or hypohidrosis

Digestive difficulties - loss of appetite, bloating unrelated to menstruation

Urinary problems - difficulty urinating, incontinence, incomplete bladder emptying Sexual dysfunction

Vision problems - blurred vision or inability for pupils to react to light quickly

Concerning autonomic abnormalities associated with puberty are shown. Adapted from Palma et al. (2017). this prevalence is likely underestimated because many do not report their symptoms (Wieling et al., 2004; Ganzeboom et al., 2006; Nordkamp et al., 2009). Episodes are often related to impaired autonomic function, and are associated with anxiety, fatigue, headaches, dizziness, abdominal discomfort, nausea, and weakness, with significant impairments in quality of life (Braune et al., 1999; Rose et al., 2000; Radtke et al., 2011; Anderson et al., 2012; Armstrong et al., 2017). In pediatric populations, morbidity is equivalent to patients with asthma, end-stage renal disease and structural heart disease (Linzer et al., 1991; Anderson et al., 2012). Recurrent episodes are associated with injury due to falls secondary to loss of postural control, and may indicate more widespread autonomic abnormalities (Hainsworth et al., 2012). Affected children find these episodes distressing and exhibit sleep disturbances and difficulty concentrating, attending and focusing at school (Carapetian et al., 2008), as well as problems with exercising and participating in activities of daily living (Braune et al., 1999; Rose et al., 2000; Radtke et al., 2011; Anderson et al., 2012; Raj, 2013; Armstrong et al., 2017). The burden on healthcare resources is also substantial, with frequent medical and emergency visits (Kanjwal and Calkins, 2015) and extensive investigation - up to $35 \%$ see 10-20 physicians before diagnosis (Armstrong et al., 2017) and 10\% of individuals still do not have a diagnosis 1 year after presenting in clinic (Van Dijk et al., 2007). Given their high incidence, marked healthcare burden, and severe impact on quality of life, a better understanding of the predisposing factors to adolescent syncope and presyncope and the potential role for pubertal hormones is warranted.

Syncope has many causes, including structural heart disease, cardiac arrhythmia, and impaired orthostatic cardiovascular control (Hainsworth et al., 2012). Here we focus on orthostatic (postural) syncope and presyncope, the most common forms in children and adolescents (Hainsworth et al., 2012). The most common sub-type of orthostatic syncope associated with puberty is vasovagal syncope (VVS) (Da and da Silva, 2014), responsible for up to $80 \%$ of pediatric syncope cases (Massin et al., 2004). Another condition that often coincides with the onset of puberty and presents with similar symptoms to VVS is Postural Orthostatic Tachycardia Syndrome (POTS) (Stewart, 2009). Both these conditions are associated with orthostatic intolerance, where the ANS does not function properly during changes in position or orthostatic stress. In broad terms, VVS reflects an excessive decrease in blood pressure and/or heart rate during orthostasis (Medow et al., 2008), while POTS displays an excessive increase in heart rate with orthostatic stress, with variable changes in blood pressure (Low, 2014).

The hormonal factors that initiate the onset and maintenance of puberty must be considered as possible culprits in the associated increased susceptibility to disorders of orthostatic intolerance, considering the timing of increased incidence of POTS and VVS with puberty (Kenny et al., 2010; Shaw et al., 2019; Figure 1). The initiation of puberty is prompted by a rise in activity of the hypothalamic-pituitary-gonadal (HPG) axis following a prolonged period of suppression 


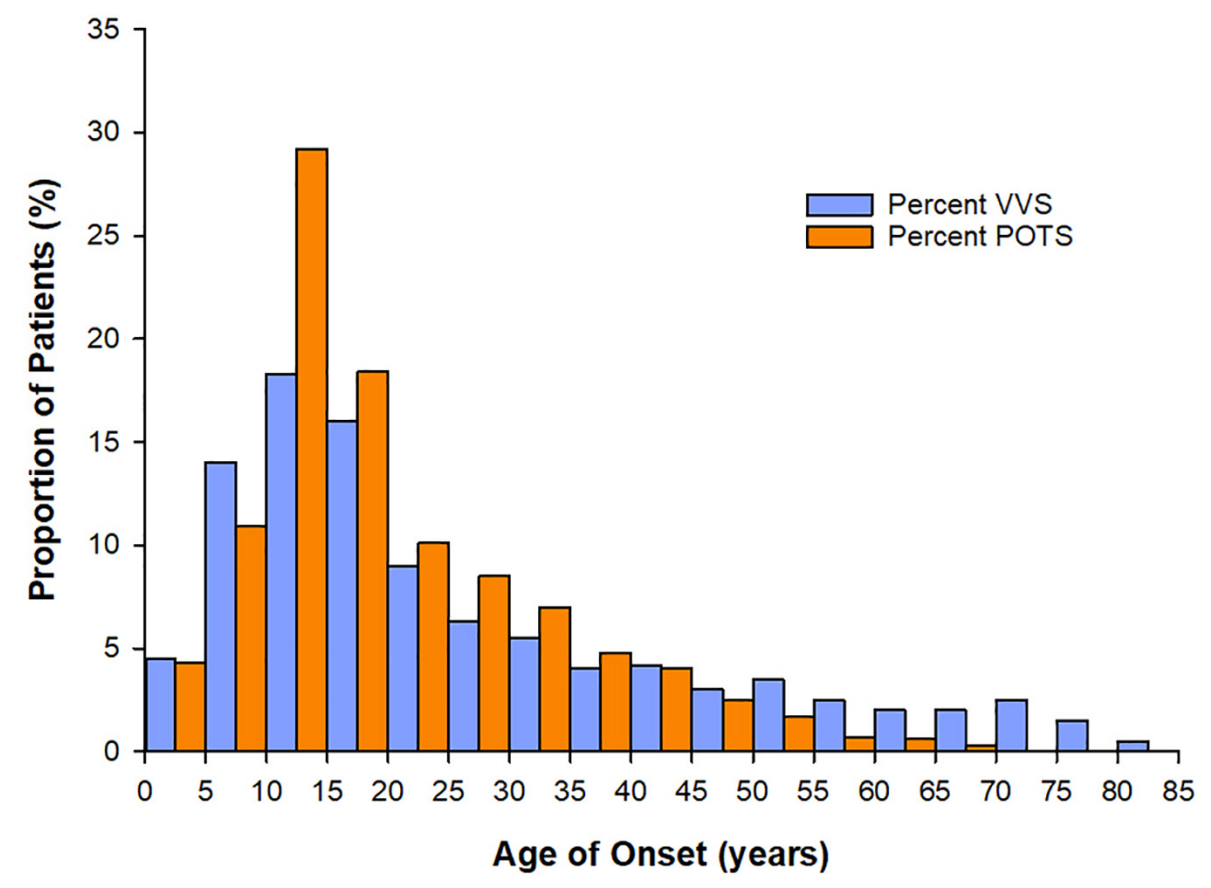

FIGURE 1 | Age at onset of vasovagal syncope (VS) and Postural Orthostatic Tachycardia Syndrome (POTS). For both patients with WS $(n=443)$ and POTS $(n=4835)$ the peak age of onset of symptoms is between 10-15 years - coinciding with the age of onset of puberty. Data sourced from Kenny et al. (2010), Shaw et al. (2019).

during childhood (Forbes and Dahl, 2010). The HPG axis increases pulsatile release of gonadotropin-releasing hormones (GnRHs), stimulating gonadal hormones, and inducing various changes throughout the body to stimulate sexual maturation (Forbes and Dahl, 2010). Puberty is further associated with changes in other non-gonadal hormones such as $\mathrm{GH}$, thyroid hormone, leptin, cortisol, and melatonin, which facilitate physical growth and behavioral changes in adolescents (Figure 2).

Females are known to have lower orthostatic tolerance compared to males (Meendering et al., 2005), with a 5:1 predominance of POTS (Low et al., 2009) and more than twice the incidence of syncope (Wieling et al., 2004). Since the initiation of puberty is prompted by a rise in activity of the HPG axis inducing changes in sex hormones (Clemans et al., 2010), it may be that some of the increased susceptibility to autonomic dysfunction in pubertal females could be attributed to hormonal changes occurring during this stage. Indeed, females with known VVS are reported to experience significant improvements in their symptoms with the introduction of hormonal therapy (Boehm et al., 1997). Orthostatic tolerance also improves in women across the lifespan, and is highest in postmenopausal females (Protheroe et al., 2013). These observations support the potential role of pubertal hormones in increasing susceptibility to cardiovascular autonomic dysfunction. Accordingly, the purpose of this review is to identify the key hormonal changes associated with female puberty, their effects on the ANS, and their potential role in predisposing adolescent females to cardiovascular autonomic dysfunctions such as VVS and POTS.

\section{Orthostasis Represents a Considerable Cardiovascular Challenge and Requires Compensation by the Autonomic Nervous System}

Orthostasis is a common trigger for VVS and POTS because when a person is upright gravitational forces decrease arterial pressures in regions above the level of the heart, while simultaneously increasing lower body venous pooling and capillary filtration, reducing venous return (Hainsworth et al., 2012). If compensation for these hemodynamic consequences of orthostasis is inadequate, cardiac output is reduced and cerebral perfusion compromised, causing symptoms of presyncope that can progress to syncope (Hainsworth et al., 2012).

Orthostatic reductions in arterial pressure are sensed primarily by baroreceptors located in the aortic arch, coronary arteries, and carotid sinus (Hall and Guyton, 2011). The carotid sinus baroreceptors are particularly important in responding to orthostatic hemodynamic changes because of their location above the heart (carotid arterial pressure is about $15 \mathrm{mmHg}$ lower than the pressure at the aortic root when upright, providing a potent stimulus to the carotid baroreceptors) (Hainsworth et al., 2012). Accordingly, during orthostasis these baroreceptors are unloaded, resulting in a reflex decrease in cardiac parasympathetic (vagal) tone, and increase in sympathetic outflow from the vasomotor center in the medulla 
to the heart and blood vessels (Hall and Guyton, 2011). The combined effect of these compensatory influences on the heart are increases in heart rate and contractility, accompanied by sympathetically mediated vasoconstriction of the resistance and capacitance vessels in the splanchnic, musculocutaneous, and renal vascular beds (Smit et al., 1999; Hall and Guyton, 2011). These coordinated adaptations are, therefore, associated with increases in total peripheral resistance, stroke volume, and blood pressure, with the maintenance of cardiac output and consequently cerebral perfusion (Medow et al., 2008). Given that these compensatory mechanisms are chiefly mediated by the ANS, impaired autonomic responses can predispose to loss of orthostatic control (Medow et al., 2008), leading to presyncope or syncope.

\section{Orthostatic Cardiovascular Responses Are Impaired in Patients With Vasovagal Syncope and Postural Orthostatic Tachycardia Syndrome}

Ultimately, the cause of orthostatic presyncope or syncope is a failure of normal cardiovascular autonomic responses. However, different patterns of responses occur representing distinct autonomic syndromes, and this complicates their diagnosis and treatment. In POTS the primary problem is excessive orthostatic tachycardia, whereas in VVS it is impaired vasoconstriction and sudden hypotension, with or without reflex bradycardia or asystole (van Lieshout et al., 1991; McLeod, 2003; Hainsworth, 2004; Brignole, 2005; Mathias et al., 2012). These abnormalities can be subdivided further and may even coexist (Kurbaan et al., 1999; Brignole et al., 2000; Schroeder et al., 2011); however, the underlying mechanisms of these disorders remain unclear, particularly in children and adolescents.

Postural Orthostatic Tachycardia Syndrome is defined as "the development of orthostatic symptoms associated with a HR increment $\geq 30 \mathrm{bpm}$ (beats per minute) $[\geq 40 \mathrm{bpm}$ in children (Singer et al., 2012; Zhao et al., 2015)], usually to $\geq 120 \mathrm{bpm}$ $[\geq 125 \mathrm{bpm}$ in children aged $13-18$ years or $\geq 130 \mathrm{bpm}$ in children aged 6-12 years (Singer et al., 2012; Zhao et al., 2015)] without orthostatic hypotension" (Low et al., 2009). It is not clear what drives the change in cardiac responsiveness and the precise age at which this change occurs is unclear; pediatric POTS has been defined for chronological ages 12 years and younger (Kurbaan et al., 1999), but this definition does not reflect physiological age or pubertal status.

Postural Orthostatic Tachycardia Syndrome includes at least four subtypes: hyperadrenergic POTS with excessive sympathetic discharge; hypovolemic POTS (with compensatory tachycardia); neuropathic POTS with impaired vasoconstriction and compensatory tachycardia; and, rarely, noradrenaline transporter deficiency with synaptic noradrenaline accumulation (Low et al., 1995, 2009; Raj, 2013). Hemodynamic subtypes of VVS have also been recognized, and are characterized according to the relative contribution of hypotension and/or bradycardia to the event (Brignole et al., 2000). These distinctions provide mechanistic insight and may inform treatment, but present similarly, so are difficult to distinguish clinically.
Whether adolescence is a time of general autonomic imbalance, and whether susceptibility to VVS and POTS are related to adolescence or pubertal hormone changes is unknown.

We and others demonstrated that in both patients with POTS and VVS, excessive venous pooling or capillary filtration (Brown and Hainsworth, 1999; Stewart et al., 2004), thermoregulatory vasodilation (Wilson et al., 2006; Hainsworth et al., 2012), low plasma or blood volumes (El-Sayed et al., 1995; Hoeldtke et al., 1995; El-Sayed and Hainsworth, 1996; Jacob et al., 1997; Mtinangi and Hainsworth, 1998, 1999; Lagi et al., 2003; Claydon et al., 2004), abnormal baroreflex responses (Thomson et al., 1997; Furlan et al., 1998; Gulli et al., 2001, 2005a,b; Cooper and Hainsworth, 2002), concurrent hypocapnia (Novak et al., 1998; Blaber et al., 2001; Carey et al., 2001; Lagi et al., 2001; Gisolf et al., 2004), excessive vascular responses to hypocapnia (Norcliffe-Kaufmann et al., 2007), and impaired cerebral autoregulation (Daffertshofer et al., 1991; Grubb et al., 1991; Claydon and Hainsworth, 2003) all increase susceptibility to orthostatic syncope in adults. In adults with VVS there is some evidence that the hypotension and reduced vascular resistance during hemodynamic collapse at presyncope may not be due to blunted sympathetic nerve activity per se but rather to other competing vasodilatory influences at that time (Vaddadi et al., 2010). There may also be an autoimmune component to susceptibility to both POTS and VVS in adults (Etienne and Weimer, 2006; Li et al., 2015; Ruzieh et al., 2017). These mechanistic insights have been central to the development of tailored management for affected adults; however, contributing mechanisms in children are less clear.

There may be a role for early excessive orthostatic cardiac sympathetic activation, and yet blunted vasoconstriction in children with POTS and VVS (Wieling et al., 1997; Moak et al., 2002; Laranjo et al., 2015; Wagoner et al., 2016), suggesting a disconnect between sympathetic outflow and the effector organ response. Indeed, some forms of POTS reflect selective neuropathy, with sympathetic denervation and impaired vascular resistance responses affecting the lower limbs (Raj, 2013). In children with VVS, initial increases in sympathetically-mediated vascular resistance responses are not sustained, and in fact abruptly reverse, precipitating hypotension (Moak et al., 2002). Orthostatic vasopressin and aldosterone are increased in children with VVS (Wagoner et al., 2016), presumably to compensate for impaired sympathetically-mediated vasoconstriction. Children with VVS and some forms of POTS have excessive venous pooling, particularly in the splanchnic vasculature (Stewart et al., 2004, 2006). Vitamin B12 deficiency (Wieling et al., 1997), low ferritin, and iron deficiency are reported in children with syncope (Antiel et al., 2011; Guven et al., 2013; Jarjour and Jarjour, 2013), presumably contributing to symptoms through anemia and low blood volumes.

Regardless of the underlying mechanism, orthostatic symptoms in children are associated with decreased cerebral blood flow velocity (Sung et al., 2000). Whether this is due to impaired cardiovascular control and compromised cerebral perfusion, or primary abnormalities in cerebral autoregulation is unclear. Interestingly, in adults with VVS cerebral pressure autoregulation is impaired (Claydon and Hainsworth, 2003) 
and combined with orthostatic hyperventilation (via activation of the respiratory muscle pump), with subsequent hypocapnia and cerebral vasoconstriction (Novak et al., 1998; Blaber et al., 2001; Carey et al., 2001; Lagi et al., 2001; Gisolf et al., 2004) that is compounded by increased cerebral reactivity to hypocapnia (Norcliffe-Kaufmann et al., 2007). The role and relative contribution of hypocapnia and cerebral autoregulation in pediatric syncope remain unclear.

Another contributor to most forms of orthostatic syncope in adults is hypovolemia, which may be associated with impaired renal sodium reabsorption in patients with POTS (Raj, 2013). Plasma or blood volume expansion improves orthostatic tolerance in adults (Rosen and Cryer, 1982; El-Sayed et al., 1995; Hoeldtke et al., 1995; El-Sayed and Hainsworth, 1996; Jacob et al., 1997; Mtinangi and Hainsworth, 1998, 1999; Lagi et al., 2003; Claydon et al., 2004; Cooper and Hainsworth, 2008), so it is possible that low plasma volumes also contribute to orthostatic syncope in children with POTS or VVS.

Lastly, physical deconditioning of the heart due to conditions such as viral infections or chronic fatigue has also been recognized as a possible mechanism underlying POTS (Fu et al., 2010). There is an association between POTS and cardiac deconditioning, and this is thought to be the result of a decreased heart size and associated decrease in cardiac output (Fu et al., 2010). The reasons why adolescent females are particularly susceptible to POTS remain unknown but perhaps their lower cardiac mass compared to adolescent males is a contributing factor.

\section{HORMONAL CHANGES DURING FEMALE PUBERTY AND THEIR INFLUENCES ON CARDIOVASCULAR AUTONOMIC CONTROL}

There are many hormonal changes during puberty that may have implications for autonomic cardiovascular control. Certainly, puberty seems to be a time of considerable change in autonomic function and cardiovascular and cerebrovascular regulation, with increases in endothelial function (Deda et al., 2015), and reductions in high frequency heart rate variability (a marker of cardiac vagal tone) in healthy adolescents following puberty (Tanaka et al., 2000). Puberty is also associated with increases in blood pressure (Tanaka et al., 2000; Deda et al., 2015), although this occurs to a much lesser extent in females than in males (Moran et al., 2008), with associated decreases in arterial stiffness during puberty in females, but not in males (Ahimastos et al., 2003). Cerebral blood flow is higher in children than in adults, and decreases markedly during puberty, with the peak reduction occurring in mid-adolescence (aged 15-17 years) - coinciding with the timing of peak incidence of syncope (Satterthwaite et al., 2014). In females, there is a partial recovery of cerebral blood flow in late puberty such that in adulthood, cerebral blood flow is greater in females compared to males (Satterthwaite et al., 2014) - coinciding with a time at which the particularly high incidence of onset of syncope in female adolescents begins to decrease. Some of these alterations in cerebral blood flow may reflect alterations in carbon dioxide levels. Higher end tidal carbon dioxide levels $\left(\mathrm{P}_{\mathrm{ET}} \mathrm{CO}_{2}\right)$ act as a potent cerebral vasodilator, increasing cerebral blood flow (Norcliffe et al., 2002; Claydon and Hainsworth, 2003). Young women breathe with an increased minute ventilation compared to young males (White et al., 1983), thus resting $\mathrm{P}_{\mathrm{ET}} \mathrm{CO}_{2}$ is significantly higher in young males relative to young females (Dhokalia et al., 1998). This may render young women more susceptible to cerebral hypoperfusion and syncope, particularly in the face of orthostatic activation of the respiratory muscle pump and further associated increases in ventilation.

\section{Qualification of Pubertal Stages in Females}

Tanner staging is a universally accepted means of qualifying pubertal development, with five proposed stages described by written criteria and illustrations (Marshall and Tanner, 1970; Swerdloff and Odell, 1975; Table 3). Tanner stage I refers to the preadolescent stage, while Tanner stage $\mathrm{V}$ represents the mature state (Marshall and Tanner, 1970). Normal timing of puberty varies and a child's chronological age is not necessarily an accurate measure of pubertal development. Therefore, where possible, hormone levels are compared based on biological maturation stages rather than age. Given that sex hormones fluctuate in females depending on the phase of the menstrual cycle, overall changes in pubertal hormones will be considered independently of menstrual timing. A summary of the key hormones involved in the regulation of female puberty is provided in Figure 2.

\section{Initiation of Puberty}

Given the common coincidental timing of onset of symptoms of autonomic impairment and puberty, it is pertinent to consider the factors at play in initiating puberty, as well as the pubertal hormones that are involved as puberty progresses. The ultimate trigger for the onset of puberty is the initiation of profound increases in pulsatile GnRH secretion from the hypothalamus. The pulsatile nature of $\mathrm{GnRH}$ secretion with the onset of puberty is important, tonic $\mathrm{GnRH}$ administration does not induce luteinizing hormone $(\mathrm{LH})$ or follicle stimulating hormone $(\mathrm{FSH})$ secretion and so prevents ovulation (Marshall and Tanner, 1970).

TABLE 3 | The Tanner stages of puberty in females.

\begin{tabular}{ll}
$\begin{array}{ll}\text { Tanner } \\
\text { stage }\end{array}$ & Description \\
\hline I & Preadolescent \\
II & Breast budding; early labial hair growth \\
III & $\begin{array}{l}\text { Increased breast size with palpable glandular tissue; no separating of } \\
\text { breast contours; moderately dark coarser labial hair over mons pubis }\end{array}$ \\
IV & $\begin{array}{l}\text { Further enlargement of breasts with projection of areola above breast } \\
\text { plane; lateral spread of pubic hair }\end{array}$ \\
& Adult breast size and pubic hair distribution
\end{tabular}

Typical stages of puberty in girls are defined according to breast development and distribution of pubic hair. Adapted from Swerdloff and Odell (1975). 


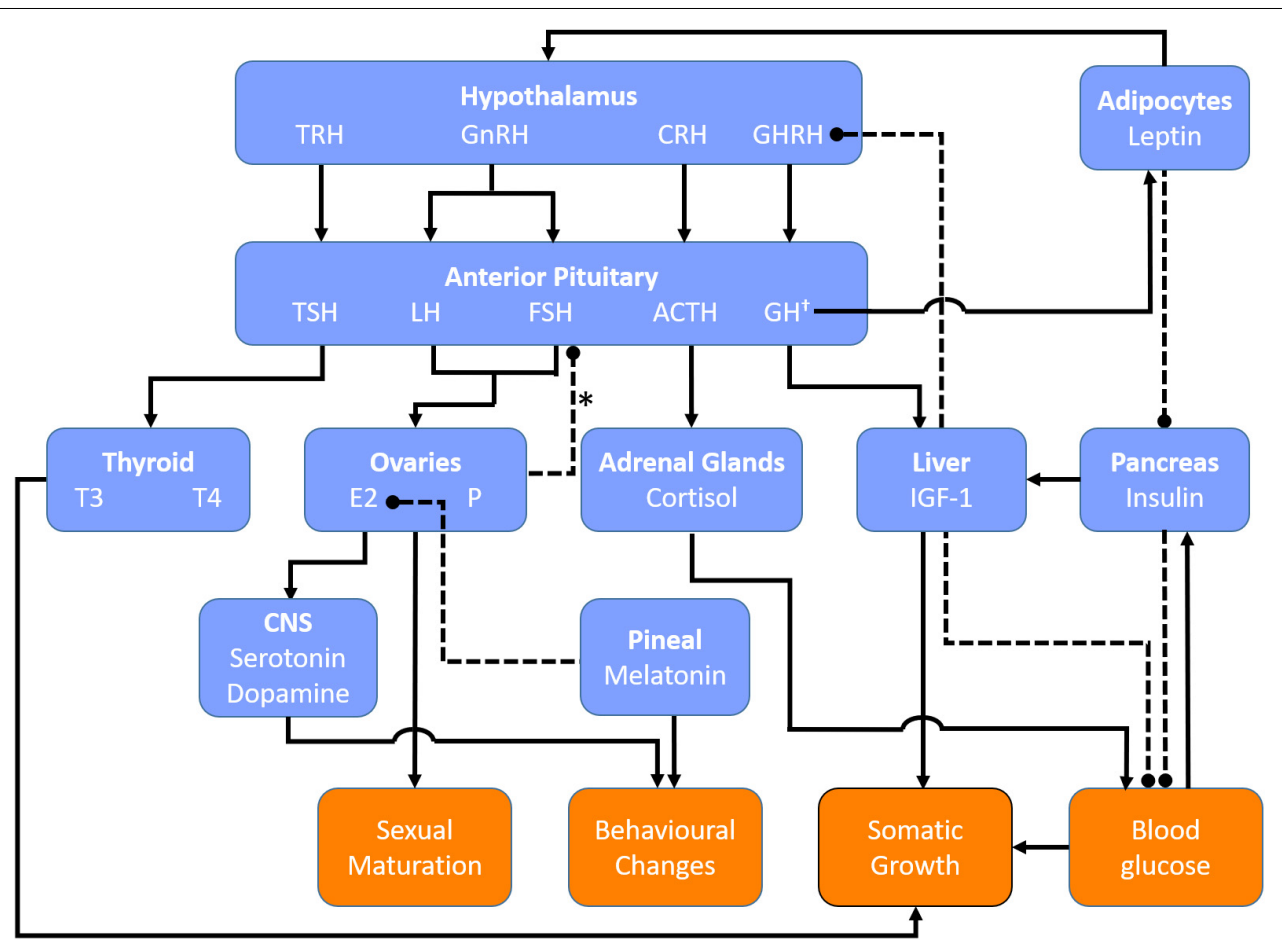

FIGURE 2 | Key regulatory hormones involved in female puberty. Blue boxes denote hormones and their source of release (bold). Orange boxes denote end organ responses. Solid lines indicate positive feedback. Dashed lines indicate negative feedback. *Negative feedback from the ovaries on FSH secretion is primarily mediated via inhibins secreted by ovarian follicles. $\dagger \mathrm{GH}$ secretion is stimulated by estrogen and thyroid hormones. ACTH, adrenocorticotrophic hormone; $\mathrm{CRH}$, corticotropin releasing hormone; CNS, central nervous system; E2, estradiol; GH, growth hormone; GHRH, growth hormone releasing hormone; GnRH, gonadotropin releasing hormone; IGF-1, insulin-like growth factor-1; P, progesterone, TRH, thyrotropin releasing hormone; TSH, thyroid stimulating hormone; T3, triiodothyronine; $\mathrm{T} 4$, thyroxine.

Numerous complementary mechanisms have been proposed to initiate the rise in pulsatile GnRH secretion (Figure 3). One key player is the loss of sensitivity to inhibition of $\mathrm{GnRH}$ secretion by ovarian sex steroids (such as estrogen and inhibins) (Gill et al., 2002; Shaw et al., 2010). Even very low levels of estrogen and inhibins block GnRH secretion in young children (Winter and Faiman, 1973). During puberty the levels of sex steroids required to block $\mathrm{GnRH}$ become progressively higher and this is permissive to increases in pulsatile $\mathrm{GnRH}$, but not sufficient to trigger puberty (Messinis, 2006).

There may be a role for nutritional status and leptin in initiating puberty. Puberty starts earlier in overweight girls, and menstruation ceases with severe weight loss (Baker, 1985). Adiposity is linked to high leptin levels, and in animals leptin supplementation advances the onset of puberty compared to pair-fed animals (necessary because of the impact of leptin on appetite) - with leptin being permissive but not sufficient for the initiation of puberty (Cheung et al., 2001). This permissive role is likely via the indirect action of leptin (mediated via decreases in the antigonadotropic hormone, $\mathrm{GnIH}$ ) on kisspeptin-expressing neurons that regulate $\mathrm{GnRH}$ secretion from the hypothalamus (Cunningham et al., 1999; Rhie, 2013). The arcuate nucleus contains abundant kisspeptin, a protein that is encoded by the Kiss1 gene, a GnRH pulse generating gene (Avendaño et al., 2017). Release of kisspeptin is inhibited until puberty when it rises and initiates increased pulsatile GnRH secretion. While it is likely that kisspeptin plays a major role in initiating puberty, the trigger for increased kisspeptin is unclear, with regulation suggested through either an internal "pubertal clock," or a "somatometer" that monitors somatic (perhaps skeletal) development and triggers kisspeptin secretion once a key developmental threshold is reached (Avendaño et al., 2017).

Melatonin secretion from the pineal gland also seems to regulate pubertal onset. Melatonin release occurs during sleep and darkness, with higher secretion during the winter when there are reduced daylight hours (Brainard et al., 1982). The human pineal gland produces a substance (s) that keeps sexual maturation in check, which may be melatonin and/or GnIH (Silman et al., 1979). Indeed, destructive tumors of the pineal gland are associated with precocious puberty, and hypersecretory tumors with delayed puberty (Kitay, 1954; Silman et al., 1979). At the onset of puberty, melatonin levels decrease and this is associated with initiation of pubertal development (Silman et al., 1979). Indeed, in children living near the equator, who have lower levels of melatonin because of the long daylight hours, puberty occurs earlier than in those at higher latitudes (Dossus et al., 2013), perhaps reflecting the role of melatonin in initiation of puberty (Murcia et al., 2002). Interestingly, the onset of pulsatile secretion of $\mathrm{GnRH}$ during puberty initially occurs only during rapid-eye-movement sleep (Shaw et al., 2015). 


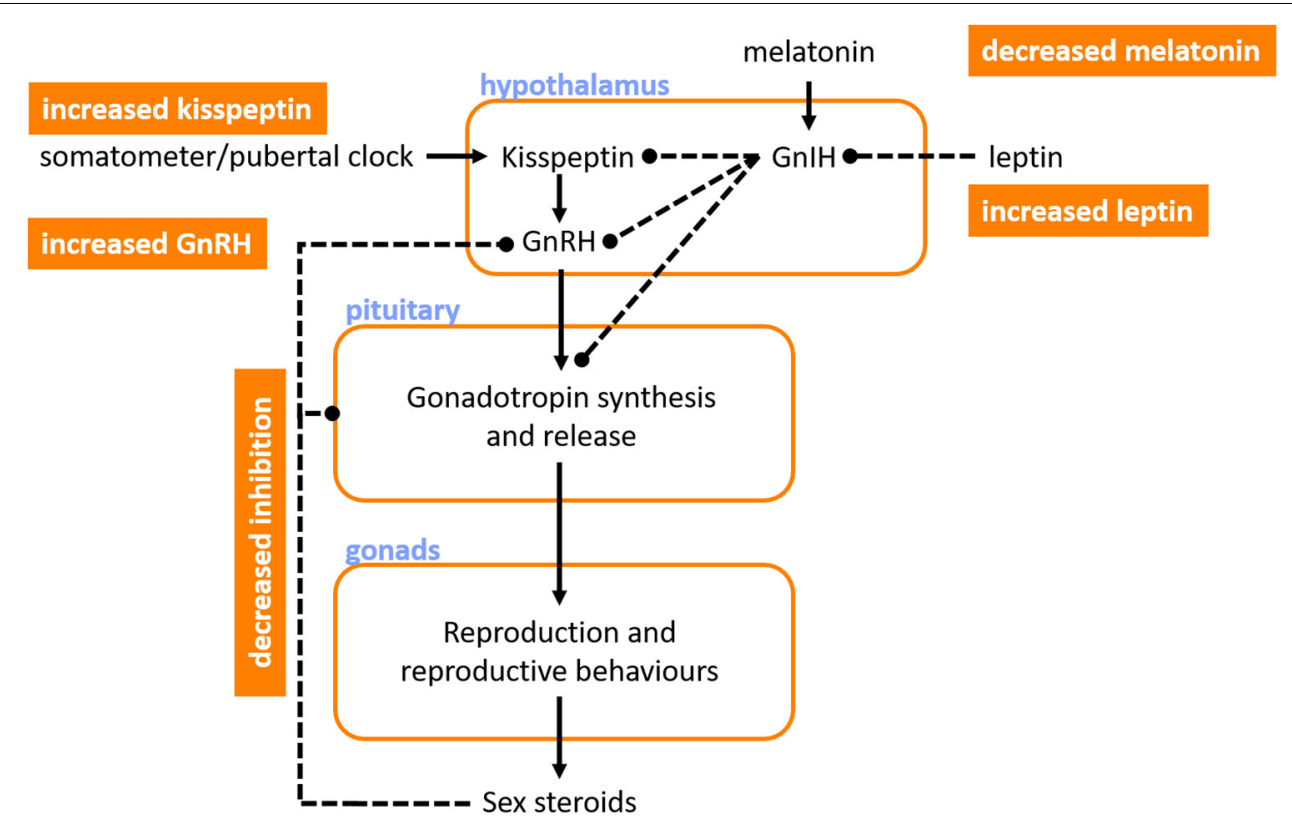

FIGURE 3 | Key hormones involved in the initiation of puberty. Ultimately, puberty is initiated by profound increases in gonadotropin releasing hormone (GnRH) that initiate cyclic synthesis and release of gonadotropins, which then regulate reproduction, reproductive behaviors and secondary sexual characteristics, and sex steroid levels. Several factors may promote the increase in $\mathrm{GnRH}$ that precedes puberty, including: reduced sensitivity to inhibition of $\mathrm{GnRH}$ secretion by the sex steroids; increased leptin, which reduces inhibition of gonadotropins and their releasing hormones by the gonadotropin inhibiting hormone (GnlH); decreases in melatonin, with an associated reduction in GnIH production; and increases in kisspeptin, perhaps triggered by a "somatometer" or "pubertal clock," which acts to further increase $\mathrm{GnRH}$ secretion. Orange boxes denote pubertal triggers. Blue text indicates sites of action or hormone release. Solid lines indicate positive feedback. Dashed lines indicate inhibitory influences.

The stimulus for this is unknown, but may involve nocturnal melatonin secretion or possibly a genetically programed state of maturity of $\mathrm{GnRH}$ secreting neurons - evidence for the latter is not yet available, but has been hypothesized given the strong correlation between the age of menses onset between mother and daughter (Kolarov et al., 2005).

Many of these key hormonal cues thought to be involved in the initiation of puberty also continue to be involved as puberty progresses, largely through their role in influencing the HPG axis.

\section{The Hypothalamic-Pituitary-Gonadal Axis}

Once puberty is initiated and the HPG axis is activated, GnRH is released from the hypothalamus (Figure 2), with peak levels at the onset of menstruation, after which its release becomes cyclical according to the phase of the menstrual cycle (Limonta et al., 2018). GnRH acts on the anterior pituitary to stimulate increases in $\mathrm{LH}$ and $\mathrm{FSH}$ production that induce sexual dimorphic changes in appearance as well as characteristic female behaviors (Limonta et al., 2018). The recent discovery of $\mathrm{GnRH}$ receptors in the ovary and endometrium raises the possibility of a role for $\mathrm{GnRH}$ outside of its hypothalamic functions (Limonta et al., 2018). LH and FSH levels increase with increases in GnRH pulse frequency and pulse amplitude during puberty. Levels of LH and FSH continue to increase until stage $\mathrm{V}$ for $\mathrm{LH}$ and stage IV for FSH, initially starting with undetectable levels of $\mathrm{LH}$ in prepubertal girls at stage I while low levels of FSH are detectable at this stage (Burger et al., 1988; Figure 4). During puberty, LH and FSH stimulate sex hormone secretion and regulate the menstrual cycle. $\mathrm{LH}$ acts on the ovaries to produce estrogen and facilitate egg maturation, while FSH is involved in follicle development and estrogen production (Limonta et al., 2018). LH also indirectly increases progesterone levels, secreted from the corpus luteum of mature follicles. Both LH and FSH appear to have indirect effects on the ANS, largely mediated through their effects on circulating estrogen and progesterone levels.

\section{Estrogen}

Increased activity of the gonads stimulated by $\mathrm{LH}$ and FSH during puberty results in an associated increased production of estrogen. During puberty, estrogen levels initially mirror LH and FSH changes, with the lowest levels in prepubertal girls at stage I (Wennink et al., 1990; Figure 4). However, similar to $\mathrm{LH}$, estrogen levels continue to increase until stage $\mathrm{V}$, during which time FSH levels begin to decline (Wennink et al., 1990). Estrogen is a sex steroid hormone that is secreted by the ovary and binds to estrogen receptors (Wennink et al., 1990). It contributes to breast, vaginal, and uterine development, as well as female fat distribution, linear growth velocity, and skeletal maturation (Swerdloff and Odell, 1975). In this review we only consider $17-\beta$ estradiol (E2) because this is the most abundant, active, and best studied form of estrogen (Rybaczyk et al., 2005; Lasiuk and Hegadoren, 2007). Other natural estrogens, estrone (E1), and estriol (E3), have weak estrogenic properties and must be 


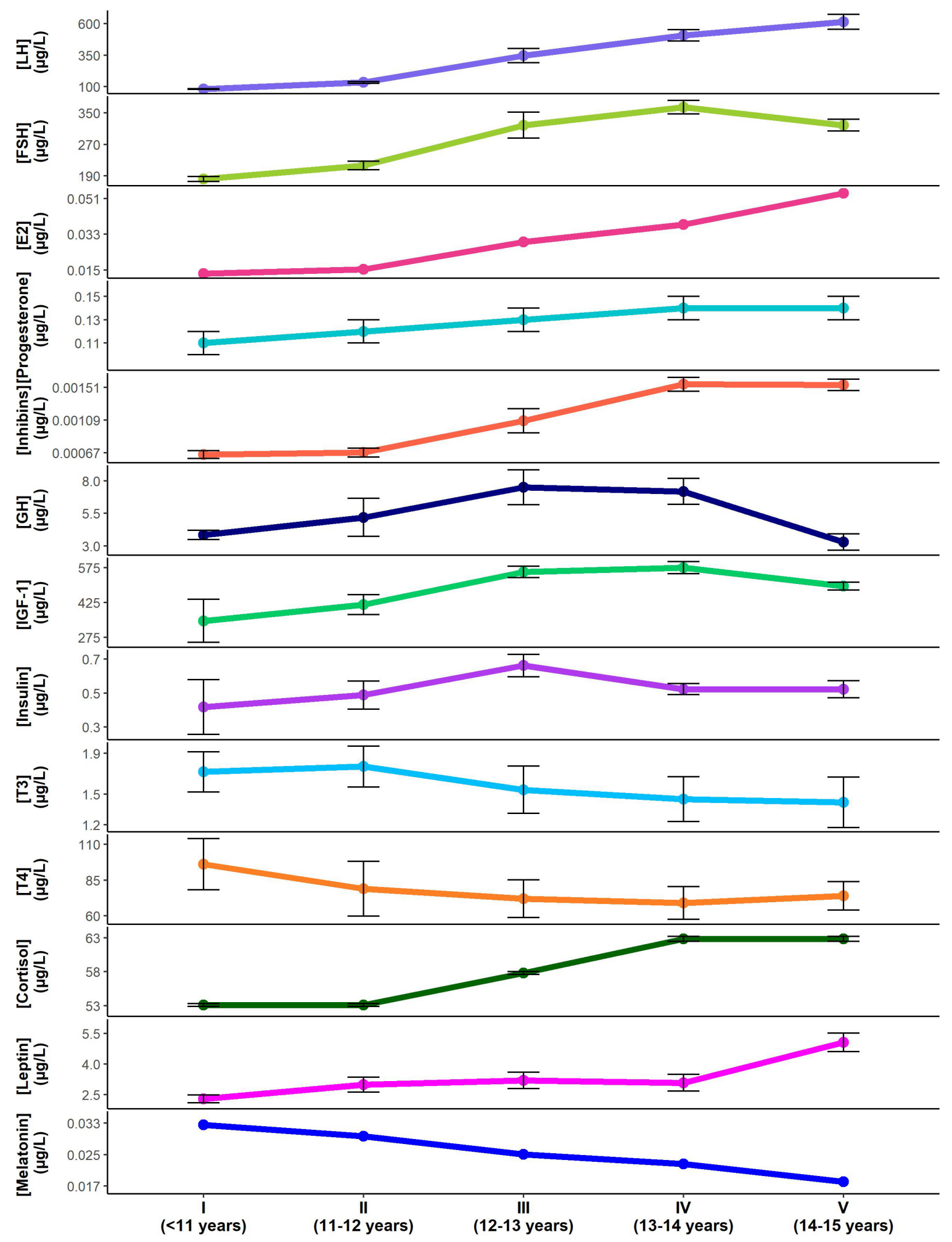

FIGURE 4 | Changes in pubertal hormone levels according to Tanner stage and approximate age (mean \pm standard error). Hormone concentrations for luteinizing hormone (LH) (Burger et al., 1988). follicle stimulating hormone (FSH) (Burger et al., 1988), Estradiol (E2) (Wennink et al., 1990), progesterone (Apter, 1980), inhibins (Wennink et al., 1990), growth hormone (GH) (Rose et al., 1991), insulin-like growth factor-1 (IGF-1) (Moran et al., 2002), insulin (Moran et al., 2002), triiodothyronine (T3) (Elmlinger et al., 2001), thyroxine (T4) (Elmlinger et al., 2001), cortisol (Stroud et al., 2011), leptin (Ahmed et al., 1999), melatonin (Crowley et al., 2012) are shown through the Tanner stages for females. Note that standard errors were not available for estradiol or melatonin data. Standard errors for LH, FSH and inhibins were approximated based on data provided. Cyclical changes in hormone levels with menstruation are not reflected. 
converted to E2 to have full estrogenic action; accordingly, they will not be considered further (Lasiuk and Hegadoren, 2007).

\section{Estrogen Promotes Vasodilation and Hypocapnia, and Reduces Plasma Volume}

Estrogen acts to acutely regulate vasomotor tone through endothelium-dependent and independent mechanisms (Mendelsohn and Karas, 1999; Maranon and Reckelhoff, 2013). E2 directly inhibits the influx of extracellular calcium into vascular smooth muscle via L-type calcium channels, preventing contraction and promoting vasodilatation (Mendelsohn and Karas, 1999). E2 also stimulates the opening of calcium-activated potassium channels through the nitric oxide (NO) and cyclic guanosine monophosphate-dependent pathways, relaxing smooth muscle and promoting vasodilatation (Mendelsohn and Karas, 1999). Lastly, E2 promotes rapid release of NO (Mendelsohn and Karas, 1999) and hydrogen sulfide (Dous et al., 2014), both of which are potent vasodilators. However, in addition to the acute effects on vasomotor tone, E2 also promotes chronic vasodilation through increased expression of endothelial nitric oxide synthase (eNOS), the enzyme that converts L-arginine to L-citrulline and NO, with a consequent vasodilatory response (Mendelsohn and Karas, 1999). In addition to promoting vasodilatation, E2 also acts to decrease plasma renin concentrations and angiotensin-converting-enzyme (ACE) with consequent reductions in plasma volume, accompanied by suppression of renal sympathetic activity, and ion and water reabsorption (Mendelsohn and Karas, 1999; Maranon and Reckelhoff, 2013). E2 also reduces circulating levels of the vasoconstrictor endothelin-1 (Mendelsohn and Karas, 1999). The net effect of these E2-mediated increases in vasodilatation and decreases in vasoconstriction and plasma volume, is a reduction in blood pressure, with the largest impact during stage $\mathrm{V}$ when E2 peaks. Interestingly, E2 enhances carotid vasomotor baroreflex sensitivity (but not cardiac baroreflex sensitivity), although this effect is likely mitigated by concurrent changes in progesterone levels, which blunt vasomotor baroreflex sensitivity (Brunt et al., 2013). Of note, estrogens have also been shown to increase cerebral blood flow in both animals and humans (Shamma et al., 1992; Belfort et al., 1995; Nevo et al., 2007), and loss of estrogens during menopause is associated with decreased cerebral reactivity (Matteis et al., 1998). The impact of vasodilation in the cerebral circulation secondary to increases in estrogen appears to be blunted in the face of estrogen and progesterone induced increases in respiration and hypocapnia, which would tend to reduce cerebral blood flow (Slatkovska et al., 2006; Preston et al., 2009).

\section{Estrogen Has Indirect Effects on Central Nervous System Modulators That Regulate Behavior and Cardiovascular Control}

Estradiol may also play a key role in regulating central nervous system factors that modulate adolescent behavior. For example, E2 may have the ability to modulate dopamine neurotransmission [dopaminergic neurons express estrogen receptors and mRNA (Purves-Tyson et al., 2012; Sinclair et al., 2014)], contributing to changes in dopamine signaling during adolescence (Sinclair et al., 2014). Dopamine is a catecholamine synthesized in dopaminergic neurons arising from the substantia nigra pars compacta and the ventral tegmental area and binds to dopamine receptor 1 (DR1) (Sinclair et al., 2014). Adult levels of DR1 mRNA and protein are attained during late adolescence/early adulthood, with coincidental timing to E2 levels (Sinclair et al., 2014). Dopamine influences control of movement, the ability to experience pleasure and pain, and emotional responses (Arain et al., 2013). In addition, dopamine inhibits noradrenaline release, and so acts to further amplify the vasodilatory effects of $\mathrm{E} 2$.

Increases in E2 have also been shown to increase serotonin concentrations by increasing the rate-limiting step in serotonin synthesis, as well as increasing the time that serotonin remains in the synapse and interstitial space (Rybaczyk et al., 2005). The latter is accomplished through the antagonistic action of E2 on the serotonin reuptake transporter (SERT) and down-regulation of SERT gene expression (Rybaczyk et al., 2005). Serotonin is an amine known to act as a neurotransmitter that is synthesized from tryptophan in serotoninergic neurons (Rybaczyk et al., 2005). Serotonin plays a role in arousal, anxiety, mood alterations and has also been shown to regulate various physiological functions including vasodilation (Arain et al., 2013). Thus, as E2 levels increase during female puberty, it is likely that these CNS modulators follow a similar increase, accounting for changes in behavior, and potentially exacerbating the vasodilatory effects of estrogen throughout puberty.

\section{Progesterone}

Progesterone secretion generally occurs in conjunction with E2, as it is regulated by gonadotropins and secreted by the ovaries and the placenta (Rossmanith et al., 1990). It binds to progesterone receptors to thicken the lining of the uterus and stimulate the formation of milk glands in the breast in preparation for pregnancy (Regidor, 2014). Progesterone remains at fairly low levels during childhood until adolescence where it is shown to increase in a cyclic manner depending on the phase of the menstrual cycle (Apter, 1980; Figure 4). Progesterone levels continue to increase and peak premenopausally, declining thereafter until reaching very low levels after menopause (O'Connor et al., 2009).

\section{Progesterone Causes Vasodilatation, Increases Plasma Volume and Promotes Hypocapnia}

The effects of progesterone in the absence of estrogen indicate that it promotes vasodilatation, blunts sympathetic outflow and increases plasma volume (Brunt et al., 2013). Progesterone stimulates NO synthesis through transcriptional and nontranscriptional pathways, promoting vasodilation (Miner et al., 2011). However, progesterone also acts to counteract the effects of estrogen on NO production, resulting in mixed evidence concerning the net role of progesterone in controlling vasomotor tone (Brunt et al., 2011). Progesterone also blunts carotidvasomotor baroreflex sensitivity (Brunt et al., 2013), but without affecting the control of mean arterial pressure, perhaps because of concurrent augmentation of baroreflex control of stroke volume and/or the opposing action of estrogen on baroreflex 
sensitivity (Brunt et al., 2011, 2013). Further research is needed to determine the precise role of progesterone in modulating vasomotor tone. However, the reported blunting of sympathetic outflow, which could account for decreases in heart rate and impaired vasoconstriction, may become relevant, particularly later in puberty.

Progesterone is a respiratory stimulant, with the consequence that $\mathrm{P}_{\mathrm{ET}} \mathrm{CO}_{2}$ levels are reduced during times of high progesterone levels. For example, ventilation is increased during the luteal phase compared to the follicular phase of the menstrual cycle (White et al., 1983). This effect is enhanced during combined increases in both estrogen and progesterone (although estrogen alone is not closely correlated with cyclic fluctuations in ventilation during the menstrual cycle) (Regensteiner et al., 1989). Accordingly, higher estrogen and progesterone levels in younger women might contribute to their lower resting $\mathrm{P}_{\mathrm{ET}} \mathrm{CO}_{2}$ in early life, and the age-related loss of estrogen would explain higher levels of $\mathrm{P}_{\mathrm{ET}} \mathrm{CO}_{2}$ in later life (Regensteiner et al., 1989). These respiratory effects of estrogen and progesterone would be expected to promote reductions in $\mathrm{P}_{\mathrm{ET}} \mathrm{CO}_{2}$ during puberty in females, particularly during the later stages, and might contribute to the reductions in cerebral blood flow that occur during female puberty.

\section{Inhibins}

Inhibin levels are increased at puberty due to increased FSH stimulation of the granulosa cells of ovarian follicles, which are the main source of circulating dimeric inhibins (Bergadá et al., 2001). During puberty, a progressive rise in inhibins accompanies an increased production of sex steroids (Bergadá et al., 2001) with the highest levels reached during stages IV-V (Burger et al., 1988; Figure 4). With the development of ovarian follicles, inhibin levels increase where they act largely to suppress FSH release (Bergadá et al., 2001). This negative feedback control of FSH secretion only occurs once adult inhibin levels are reached (Bergadá et al., 2001).

\section{Inhibins Regulate Follicle Stimulating Hormone Levels and Indirectly Affect Estrogen Levels}

Once adult inhibin levels are reached at around stage IV, inhibins indirectly modulate estrogen levels through negative feedback control of FSH (Bergadá et al., 2001), with a theoretical impact on cardiovascular regulation via estrogen (Figure 2). However, E2 continues to increase from stage IV to $\mathrm{V}$, indicating that the role of inhibin on overall estrogen levels is small. Inhibins play a key role in regulating estrogen levels during the menstrual cycle, but do not appear to affect the overall estrogen levels during the stages of puberty. Direct effects of inhibins on cardiovascular regulation have not been demonstrated, although they may play a role in gestational hypertension and preeclampsia (Itoh et al., 2006).

\section{Growth Hormone}

Growth hormone (GH) increases substantially during the growth spurt of adolescence. It is secreted by the anterior pituitary gland in response to stimulation by $\mathrm{GH}$ releasing hormone from the hypothalamus (Soliman et al., 2014). GH levels more than double during puberty (Saenger, 2003), attaining peak levels at stage IIIIV in females (Rose et al., 1991; Soliman et al., 2014; Figure 4). $\mathrm{GH}$ functions to promote lipolysis, increase protein synthesis, regulate energy metabolism in liver, muscle and adipose tissue, and is a potent insulin antagonist (Sakharova et al., 2008). GH levels are exquisitely regulated, with secretion enhanced by estrogen and thyroid hormones, and further regulation by somatostatin, ghrelin, and insulin-like growth factor 1 (IGF-1) levels. Circulating $\mathrm{GH}$ levels also regulate $\mathrm{GH}$ secretion through negative feedback (Romero et al., 2012).

\section{Growth Hormone Is a Vasodilator and Induces Insulin-Resistance}

Growth hormone acts as a vasodilator through activation of an endothelium-dependent component involving the NO pathway (Napoli et al., 2003) to improve arterial compliance, flow mediated dilation, and endothelial function (Napoli et al., 2003). Given its vasodilatory effects, GH would be expected to contribute to blood pressure lowering, particularly during stage III-IV where GH levels reach their peak. However, GH also acts to antagonize the hepatic and peripheral effects of insulin on glucose metabolism, preventing insulin uptake and inducing insulin resistance, thus increasing circulating insulin levels (Palmeiro et al., 2012). Furthermore, GH has a significant influence on adipocyte metabolism, increasing adipokines such as leptin (Palmeiro et al., 2012). Accordingly, GH contributes to increases in both insulin and leptin, increasing their impact on autonomic cardiovascular regulation.

\section{Insulin-Like Growth Factor-1}

Insulin-like growth factor-1 (IGF-1) production follows similar patterns to $\mathrm{GH}$ secretion during puberty; it is stimulated by $\mathrm{GH}$ in the liver and further enhanced by estrogen and thyroid hormones (Rozario et al., 2000). In females, IGF-1 levels peak during stage IV and are associated with increases in adiposity at this time (Moran et al., 2002; Figure 4). IGF-1 binds to the IGF-1 receptor and is a primary mediator of the actions of $\mathrm{GH}$, promoting growth in almost every cell in the body by regulating cellular proliferation, differentiation and metabolism (Rozario et al., 2000).

\section{Insulin-Like Growth Factor-1 Is a Vasodilator and Enhances Insulin Sensitivity}

Insulin-like growth factor-1 induces vasodilation by enhancing $\mathrm{NO}$ and potassium channel activity, both of which reduce calcium release into vascular smooth muscle, blunting vasoconstriction (Conti et al., 2004). IGF-1 interacts with a tyrosine kinase membrane receptor that activates the serine/threonine kinase Akt signaling pathway, which in turn activates eNOS, increasing NO levels and promoting vasodilatation (Conti et al., 2004). By facilitating widespread vasodilatation, it is likely that IGF-1 reduces blood pressure, particularly during stage III-IV when IGF-1 levels peak. IGF-1 increases insulin sensitivity and prevents postprandial dyslipidemia by suppressing plasma free fatty acid levels, reducing fasting plasma triglyceride concentrations, and increasing oxidative and non-oxidative glucose metabolism 
(Conti et al., 2004). Contrary to GH, IGF-1 helps to restore insulin and leptin levels to normal values (Conti et al., 2004). Thus, increases in IGF-1 are likely the result of, not the cause of, insulin resistance in puberty (Kelsey and Zeitler, 2016).

\section{Insulin}

During female puberty insulin levels generally coincide with changes in IGF-1 levels (Moran et al., 2002). Fasting insulin levels are highest in stage III, occurring one stage earlier than peak IGF1 levels (Moran et al., 2002; Figure 4). Insulin is synthesized by beta cells in the pancreas following stimulation by blood glucose (Sliwowska et al., 2014)and primarily acts to facilitate cellular glucose entry for energy utilization and growth (Sliwowska et al., 2014). When this process is compromised, insulin resistance can develop, and if left untreated it can progress to type 2 diabetes mellitus.

Puberty is associated with a marked decrease in insulin sensitivity, on par with that seen during pregnancy. In otherwise healthy youth, insulin sensitivity reaches a nadir in mid-puberty (stage III) that recovers by stage V (Kelsey and Zeitler, 2016). In patients with POTS, increases in serum resistin have been documented, the significance of which is unclear, but it has been previously associated with insulin resistance (Bai et al., 2017). It is interesting to note that the decline in cerebral blood flow during puberty is tightly linked to the concurrent decreases in glucose metabolism (Satterthwaite et al., 2014).

In children with type 1 diabetes, profound insulin resistance associated with puberty is well documented, although effects on the ANS in these children are not well studied. In one study evaluating 73 diabetic children, abnormalities in heart rate variability (a marker of autonomic dysfunction) were correlated with poor glycemic control in pubertal children. This relationship was not seen in younger children (Massin et al., 1999).

\section{Insulin Exhibits Opposing Roles in Regulating Vasomotor Tone}

Insulin exhibits both central and peripheral effects on the ANS - insulin both promotes vasodilatation and prevents vasoconstriction, while also having the ability to stimulate sympathetic activity. Insulin diminishes arterial stiffness (Vehkavaara et al., 2000) and acts as a vasodilator by binding to an insulin receptor tyrosine kinase, activating the Akt pathway and further stimulating eNOS to increase NO production (Muniyappa et al., 2007). Insulin has further been shown to attenuate vascular smooth muscle contraction and decrease vasoconstrictor tone by inhibiting calcium influx (Muniyappa et al., 2007). In contrast, insulin can stimulate sympathetic activity and increase catecholamine levels (Muniyappa et al., 2007). The opposing roles of insulin essentially lead to little change in arterial diameter and blood pressure under normal circumstances in healthy individuals (Muniyappa et al., 2007). However, during acute increases in sympathetic nerve activity, different parts of the vascular tree respond differently to insulin, where distal arterioles vasodilate and proximal arterioles constrict (Muniyappa et al., 2007). This could contribute to enhanced venous pooling during sympathetic activation upon standing. Increases in sympathetic activity and catecholamine levels would tend to facilitate tachycardia.

\section{Thyroid Hormones}

The thyroid gland produces triiodothyronine (T3) and thyroxine (T4), both of which are stimulated by thyroid-stimulating hormone from the anterior pituitary gland secondary to release of thyrotropin-releasing hormone from the hypothalamus (Shahid and Sharma, 2019). The release of T3 and T4 from the thyroid gland is influenced by growth factors and modulated by sex steroids in females (Dunger et al., 1990). During puberty T3 increases, peaking during stage II, while T4 decreases at the onset of puberty and continues to decrease before leveling off after stage IV (Dunger et al., 1990; Elmlinger et al., 2001; Figure 4). The decrease in T4 is likely a result of its conversion into T3 in the periphery, as T3 is the more active, bioavailable form of thyroid hormone (Jørgensen et al., 1994). These hormones act to increase and regulate basal metabolic rate, as well as to increase heart rate, cardiac output, and ventilation, with decreases in peripheral resistance (Shahid and Sharma, 2019). Additional effects on the central nervous system and skeleton are crucial to normal development and growth (Shahid and Sharma, 2019).

\section{Thyroid Hormones Act as Vasodilators While Increasing Heart Rate to Preserve Blood Pressure}

Higher levels of thyroid hormones increase metabolism and heat production stimulating hypothalamic reflex responses (Thomas, 1957). These hypothalamic responses initiate vasodilation of arterioles, largely in the skin, to increase blood flow and dissipate heat, while simultaneously increasing heart rate and stroke volume to maintain a constant blood pressure (Thomas, 1957). T3 enhances endothelium-dependent relaxation through a cyclic adenosine monophosphate-mediated increase in endothelium-derived hyperpolarizing factor (EDHF), as well as through NO-mediated relaxation via up-regulation of eNOS (Büssemaker et al., 2003). EDHF prevents calcium influx through voltage-gated calcium channels, inhibiting contraction of vascular smooth muscle. T4 directly inhibits vascular contraction by inhibiting calcium/calmodulin-related regulatory mechanisms (Ishikawa et al., 1989). Cerebral blood flow remains unchanged during increases in thyroid hormones (Thomas, 1957).

\section{Cortisol}

Baseline cortisol levels increase during puberty, peaking at stage IV/V in females (Stroud et al., 2011; Figure 4). Cortisol is released by the adrenal gland following stimulation by adrenocorticotropic hormone, which is produced by the anterior pituitary (Lee et al., 2015). Cortisol binds to cortisol receptors and plays a role in maintaining blood glucose levels, central nervous system function, and cardiovascular function during fasting (Lee et al., 2015). Cortisol increases blood glucose levels during stress at the expense of muscle protein and one of its most important functions is to protect the body against self-injurious inflammatory and immune responses (Lee et al., 2015). 


\section{Cortisol Increases Plasma Volume and Increases Blood Pressure}

Acute increases in cortisol levels blunt autonomic reactivity by suppressing the early effects of catecholamines in the brain (Teixeira et al., 2015), with subsequent decreases in arterial vasoconstriction (Theodorakis et al., 1998). However, chronic elevations in cortisol induce hypertension, independent of changes in sympathetic nervous system activity, likely mediated via increases in plasma volume, extracellular fluid and exchangeable sodium (Theodorakis et al., 1998).

\section{Leptin}

Leptin levels increase with the onset of puberty, but remain fairly steady following this initial rise until a late surge starting at stage IV in females (Ahmed et al., 1999; Figure 4). Leptin is secreted by adipocytes and is hypothesized to act on specific receptors at the level of the hypothalamus to regulate appetite, energy expenditure, the neuroendocrine axis, and weight (Ahmed et al., 1999). Differential changes in body composition between males and females during puberty are affected by the sexual dimorphism of leptin levels during this period (Ahmed et al., 1999). In females, leptin increases throughout puberty, with a prominent surge during stage IV$\mathrm{V}$, to reach adult concentrations, while in males it increases only transiently with the onset of puberty (Kelsey and Zeitler, 2016).

\section{Leptin Activates the Sympathetic Nervous System and Increases Insulin Sensitivity}

Leptin activates the sympathetic nervous system through hypothalamic mechanisms that are mediated by neuropeptide systems, including the melanocortin system and corticotropinreleasing hormone (Muniyappa et al., 2007). With increases in sympathetic activity, increases in heart rate and vasoconstriction are expected, particularly at stage $\mathrm{V}$, when leptin levels peak. Leptin also increases insulin sensitivity which helps to prevent abnormally high levels of circulating insulin, and somewhat counteracts the role of $\mathrm{GH}$ in inducing insulin-resistance (Muniyappa et al., 2007). Higher leptin levels are also associated with impaired heart rate variability (a sign of autonomic dysfunction). In particular, increased low frequency heart rate variability, and an increased ratio of low to high frequency heart rate variability have been reported, suggesting that increased leptin levels may result in an autonomic imbalance with a sympathetic predominance in young females during puberty (Van De Wielle and Michels, 2017).

\section{Melatonin}

In the early stages of female puberty (I and II) melatonin secretion significantly decreases, with further successive decreases in the later stages (Murcia et al., 2002; Crowley et al., 2012; Figure 4). Melatonin is a lipophilic endocrine hormone that is synthesized in the pineal gland (Murcia et al., 2002). Melatonin secretion is largely regulated by light and dark information received by the suprachiasmatic nucleus from retinal photosensitive ganglionic cells (Murcia et al., 2002). It is secreted in a circadian pattern, with the greatest secretions occurring at night (Murcia et al., 2002), and functions in many regulatory processes including biological rhythms, metabolism, intestinal reflexes, and protection against inflammation (Chen et al., 2011).

\section{Melatonin Inhibits Estrogen Receptor-Mediated Transcription}

Melatonin interferes with E2 signaling by impairing estrogen receptor pathways via specific inhibition of E2-induced estrogen receptor alpha $(\mathrm{ER} \alpha)$ mediated transcription of both estrogen response element and activator protein 1 containing promoters (Del Río et al., 2004). By reducing the transcription of one of the main estrogen receptors, ER $\alpha$, the effects of estrogen are reduced. As melatonin levels decrease as puberty progresses, while estrogen increases, there is an inverse relationship between melatonin and estrogen. Thus, the inhibitory effect of melatonin on estrogen signaling is probably relatively minor during puberty.

\section{Kisspeptin and Gonadotropin Inhibiting Hormone}

Increases in kisspeptin levels and decreases in $\mathrm{GnIH}$ levels are thought to contribute to the initiation of puberty (Figure 3). However, data on kisspeptin and GnIH levels throughout

TABLE 4 | Impact of pubertal hormones on factors that predispose to syncope events.

\begin{tabular}{|c|c|c|}
\hline $\begin{array}{l}\text { Factors predisposing } \\
\text { orthostatic intolerance }\end{array}$ & $\begin{array}{l}\text { Pubertal hormones } \\
\text { that exacerbate }\end{array}$ & $\begin{array}{l}\text { Pubertal hormones that } \\
\text { ameliorate }\end{array}$ \\
\hline \multirow[t]{6}{*}{ Vasodilatation } & Estrogen & $\begin{array}{l}\text { Progesterone (by inhibiting } \\
\text { action of estrogen) }\end{array}$ \\
\hline & Progesterone & $\begin{array}{l}\text { Melatonin (by inhibiting } \\
\text { action of estrogen) }\end{array}$ \\
\hline & Growth hormone & \\
\hline & IGF-1 & \\
\hline & Insulin & \\
\hline & Thyroid hormones & \\
\hline \multirow[t]{2}{*}{ Impaired vasoconstriction } & Insulin & Leptin \\
\hline & Progesterone & \\
\hline \multirow[t]{3}{*}{ Hypotension } & Estrogen & Cortisol \\
\hline & Growth hormone & \\
\hline & IGF-1 & \\
\hline \multirow[t]{2}{*}{ Low sympathetic activity } & Progesterone & Leptin \\
\hline & & Insulin \\
\hline Excessive venous pooling & Insulin & \\
\hline \multirow[t]{2}{*}{ Hypovolemia } & Estrogen & Cortisol \\
\hline & & Progesterone \\
\hline \multirow[t]{2}{*}{ Hypocapnia } & Estrogen & \\
\hline & Progesterone & \\
\hline $\begin{array}{l}\text { Decreased cerebral blood } \\
\text { flow }\end{array}$ & $\begin{array}{l}\text { Estrogen and } \\
\text { progesterone (via } \\
\text { hypocapnia) }\end{array}$ & Estrogen \\
\hline \multirow[t]{3}{*}{ Excessive tachycardia } & Insulin & Progesterone \\
\hline & Leptin & \\
\hline & Thyroid hormones & \\
\hline $\begin{array}{l}\text { Decreased baroreflex } \\
\text { sensitivity }\end{array}$ & Progesterone & Estrogen \\
\hline
\end{tabular}

IGF-1, insulin-like growth factor-1. 
the phases of puberty, as well as any potential impact on cardiovascular responses or susceptibility to syncope are currently lacking.

\section{PUBERTAL HORMONES AS POTENTIAL CONTRIBUTORS TO VASOVAGAL SYNCOPE AND POSTURAL ORTHOSTATIC TACHYCARDIA SYNDROME}

There are numerous factors known to increase susceptibility to syncope. One key contributor is excessive vasodilatation and/or impaired vasoconstrictor responses, often associated with hypotension and blunted sympathetic outflow (Brown and Hainsworth, 2000; Bush et al., 2000). In addition, hypocapnia and cerebral hypoperfusion (Claydon and Hainsworth, 2003; Norcliffe-Kaufmann et al., 2007), hypovolemia (Cooper and Hainsworth, 2008), excessive tachycardia (Sandroni et al., 1999), or impaired baroreflex responses (Cooper and Hainsworth, 2002;
Gulli et al., 2005a), will all impair orthostatic cardiovascular control. The potential impact of female pubertal hormones on these predisposing factors is summarized in Table 4.

The implications for these hormones as possible contributors to VVS and POTS can be considered based on the impact each has on cardiovascular control (Table 4), and the timing of their changes over the duration of puberty (Apter, 1980; Burger et al., 1988; Wennink et al., 1990; Rose et al., 1991; Ahmed et al., 1999; Elmlinger et al., 2001; Moran et al., 2002; Stroud et al., 2011; Crowley et al., 2012; Figure 4). Hormones promoting vasodilatation may exacerbate the inappropriate reductions in blood pressure that occur during VVS or the impaired vasoconstriction in POTS, placing increased reliance on orthostatic tachycardia for maintenance of blood pressure (Figures 5, 6). Thyroid hormones, GH and IGF-1 largely act as vasodilators through their involvement with the NO pathway. Along with releasing $\mathrm{NO}$ and hydrogen sulfide, another vasodilator, E2 also promotes hyperpolarization in vascular smooth muscle, and decreases renal renin release with subsequent reductions in angiotensin-mediated vasoconstriction, culminating in a potent vasodilatory influence. Baseline blood

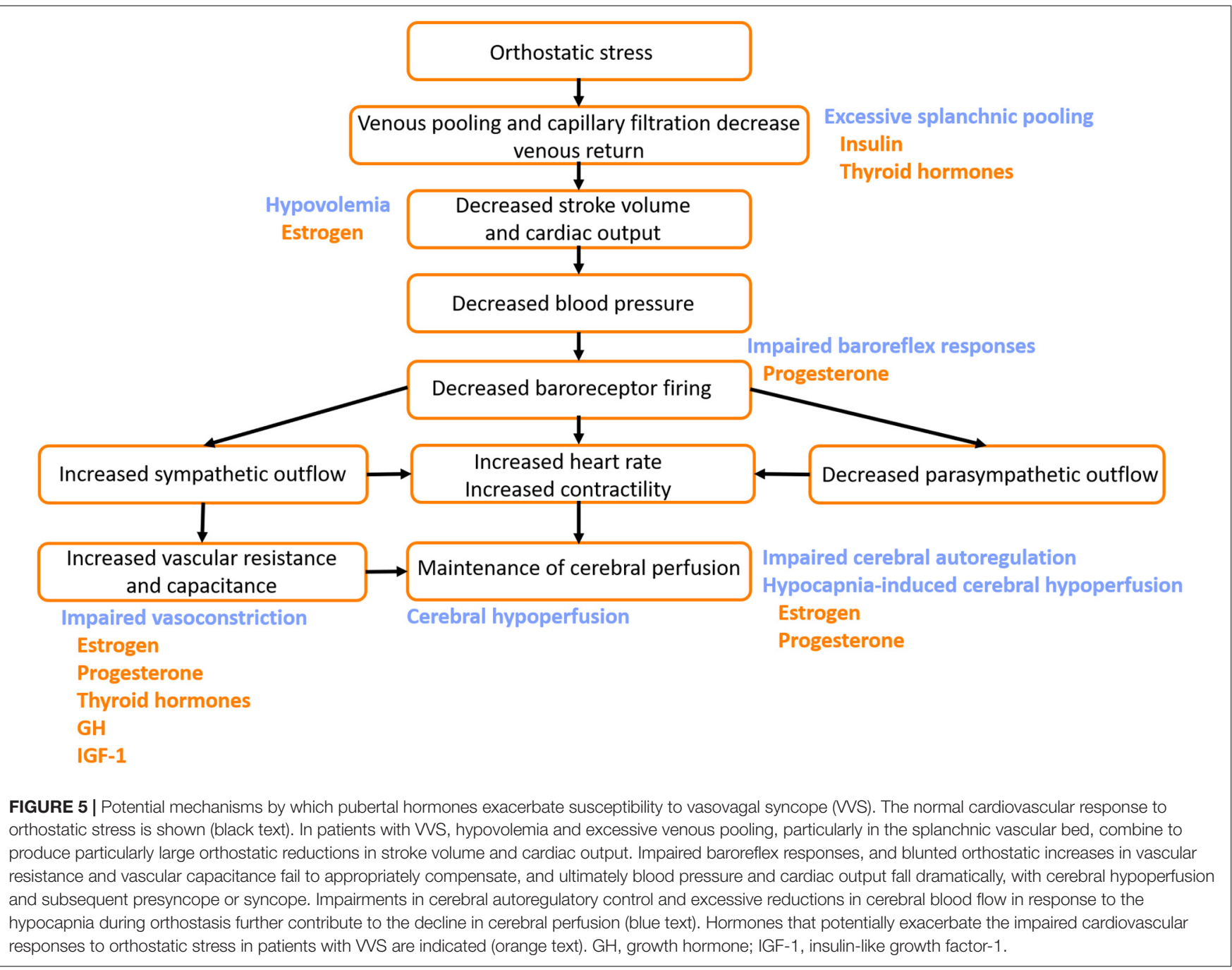




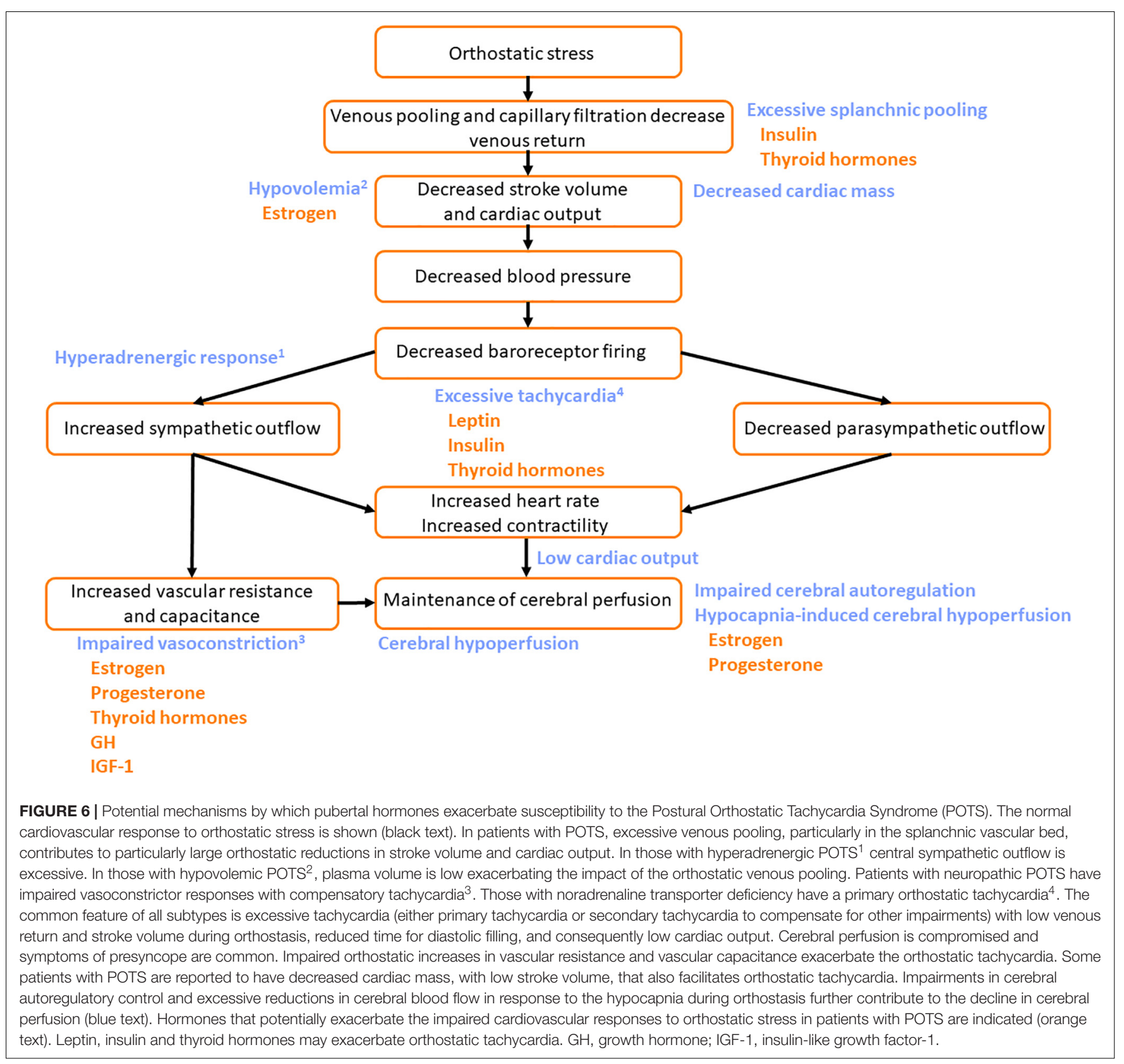

pressures increase during puberty, but to a lesser degree in females than in males, suggesting that the vasodilatory actions of female pubertal hormones promote lower blood pressures in females, with an associated susceptibility to further orthostatic blood pressure decrements (Shankar et al., 2005). The differential influence of insulin in the presence of sympathetic stimulation may account for the abnormal blood perfusion and splanchnic pooling as a proposed mechanism of VVS and POTS (Figures 5, 6). In the presence of high insulin and sympathetic activity, as seen with standing, distal vessels vasodilate while proximal vessels constrict, likely increasing blood flow to distal extremities while decreasing flow to the central regions of the body. This effect would predominate during stage III when insulin levels peak. Similarly, different organs in the body respond differently to the vasodilatory effects of thyroid hormones, and this may also promote splanchnic pooling (Figures 5, 6). The presence of hypovolemia in POTS and VVS patients may be exacerbated by E2 as it acts to decrease renin concentrations with consequent decreases in blood volume mediated via the renin-angiotensinaldosterone pathway. High levels of E2 and progesterone may promote hypocapnia and associated reductions in cerebral blood flow, increasing susceptibility to further cerebral compromise during orthostatic stress. While these hormones can account for some of the similar predisposing factors and symptoms of VVS and POTS, hormones that may contribute to the different profiles of VVS and POTS should further be considered. 
The effects of these hormones on the ANS may be more prominent in some individuals, leading to a greater predisposition to POTS or VVS. As cortisol levels have been shown to increase during vasovagal reactions in patients with VVS (Stroud et al., 2011), peak levels of cortisol during stage IV/V may play a role in the manifestation of VVS. Progesterone may also be a contributor to VVS by blunting sympathetic outflow, and impairing baroreflex responses, exhibiting its greatest effects during stages IV-V, when progesterone is at its highest (Figure 5).

Central hyperadrenergic POTS and the abnormal heart rate increases in POTS patients could be exacerbated by hormones involved in increasing sympathetic activity and elevating norepinephrine levels (Figure 6). Both insulin and leptin have the ability to increase sympathetic activity and stimulate catecholamine release, and increases in leptin and insulin are associated with increases in heart rate. Insulin and leptin peak during puberty in stages III and V, respectively, and might be hypothesized to exacerbate orthostatic tachycardia at these times. Thyroid hormones also play a role in increasing heart rate to maintain blood pressure - with key rises in T3 during pubertal stage II.

While it is certainly not possible to imply causality between these pubertal hormone changes and disorders of orthostatic tolerance in adolescents, the coincidental timing of these profound hormonal changes - many of which have marked cardiovascular effects - and the timing of onset of VVS and POTS, together with the observation that many youth "grow out" of their symptoms (Kizilbash et al., 2014), is suggestive of a link between pubertal hormone changes and susceptibility to syncope in females. Certainly, orthostatic tolerance increases in women as they age, and is highest in postmenopausal women (Protheroe et al., 2013). It is conceivable that pubertal increases in these hormones, many of which have secondary actions to promote vasodilatation, impair vasoconstriction, decrease blood volume, promote hypocapnia and cerebral hypoperfusion, and contribute to excessive tachycardia, unmask a susceptibility to disorders of orthostatic intolerance in girls with a previously unknown predisposition to poor orthostatic tolerance. Further insight into the role of female sex hormones in susceptibility to VVS and POTS can also be gleaned from a case series in which fifteen women (including six adolescents) with refractory VVS/POTS experienced symptomatic benefit with complete resolution, or

\section{REFERENCES}

Ahimastos, A. A., Formosa, M., Dart, A. M., and Kingwell, B. A. (2003). Gender differences in large artery stiffness pre- and post puberty. J. Clin. Endocrinol. Metab. 88, 5375-5380. doi: 10.1210/jc.2003-03 0722

Ahmed, M. L., Ong, K. K., Morrell, D. J., Cox, L., Drayer, N., Perry, L., et al. (1999). Longitudinal study of leptin concentrations during puberty: sex differences and relationship to changes in body composition. J. Clin. Endocrinol. Metab. 84, 899-905. doi: 10.1210/jc.84.3.899

Anderson, J. B., Czosek, R. J., Knilans, T. K., and Marino, B. S. (2012). The effect of paediatric syncope on health-related quality of life. Cardiol. Young 22, 583-588. doi: 10.1017/S1047951112000133

Antiel, R. M., Caudill, J. S., Burkhardt, B. E. U., Brands, C. K., and Fischer, P. R. (2011). Iron insufficiency and hypovitaminosis D in adolescents with chronic a marked reduction in the frequency, of orthostatic symptoms following ovarian hormone therapy (Boehm et al., 1997).

\section{CONCLUSION}

Hormone changes during puberty have the potential to impact cardiovascular autonomic control and as such may play a role in predisposing adolescent females to autonomic dysfunction, including disorders of orthostatic intolerance such as POTS and VVS. The peak incidence of VVS and POTS in young women occurs at approximately 10-15 years of age, a time where many hormones involved in puberty, capable of predisposing to disorders of orthostatic intolerance, are at peak levels. These pubertal hormones can act to promote vasodilatation, impair vasoconstriction, decrease plasma volume, promote hypocapnia and cerebral hypoperfusion, and contribute to excessive tachycardia. Additional research is necessary to examine the potential role that puberty, and in particular the hormonal changes that accompany it, may have in predisposing young females to orthostatic intolerance and autonomic dysfunction during their pubertal years.

\section{AUTHOR CONTRIBUTIONS}

$\mathrm{KC}, \mathrm{NH}, \mathrm{BH}$, and $\mathrm{VC}$ wrote the manuscript. RR, KA, and SS provided critical analysis, insight, editing, and review of intellectual content.

\section{FUNDING}

This work was supported by a grant-in-aid (G-18-0022174) from the Heart and Stroke Foundation of Canada (VC).

\section{ACKNOWLEDGMENTS}

We are grateful to Ms. Rebekah Lee for her assistance in coordinating reference databases. We thank Dr. Shazan Amed for her help with conceptualization of the manuscript.

fatigue and orthostatic intolerance. South. Med. J. 104, 609-611. doi: 10.1097/ SMJ.0b013e3182246809

Apter, D. (1980). Serum steroids and pituitary hormones in female puberty: a partly longitudinal study. Clin. Endocrinol. 12, 107-120. doi: 10.1111/j.1365-2265. 1980.tb02125.x

Arain, M., Haque, M., Johal, L., Mathur, P., Nel, W., Rais, A., et al. (2013). Maturation of the adolescent brain. Neuropsychiatr. Dis. Treat. 9, 449-461. doi: 10.2147/NDT.S39776

Armstrong, K. R., De Souza, A. M., Sneddon, P. L., Potts, J. E., Claydon, V. E., and Sanatani, S. (2017). Exercise and the multidisciplinary holistic approach to adolescent dysautonomia. Acta Paediatr. 106, 612-618. doi: 10.1111/apa.13750

Avendaño, M. S., Vazquez, M. J., and Tena-Sempere, M. (2017). Disentangling puberty: novel neuroendocrine pathways and mechanisms for the control of mammalian puberty. Hum. Reprod. Update 23, 737-763. doi: 10.1093/humupd/ dmx025 
Bai, W., Han, Z., Chen, S., Li, H., Song, J., Qi, J., et al. (2017). Serum resistin negatively correlates with clinical severity of postural tachycardia syndrome in children. Pediatr. Cardiol. 38, 1639-1644. doi: 10.1007/s00246-017-1708-4

Baker, E. R. (1985). Body weight and the initiation of puberty. Clin. Obstet. Gynecol. 28, 573-579. doi: 10.1097/00003081-198528030-00013

Belfort, M. A., Saade, G. R., Snabes, M., Dunn, R., Moise, K. J., Cruz, A., et al. (1995). Hormonal status affects the reactivity of the cerebral vasculature. Am. J. Obstet. Gynecol. 172(4 Pt 1), 1273-1278. doi: 10.1016/0002-9378(95)91492-7

Bergadá, I., Bergadá, C., and Campo, S. (2001). Role of inhibins in childhood and puberty. J. Pediatr. Endocrinol. Metab. 14, 343-353.

Blaber, A. P., Bondar, R. L., Moradshahi, P., Serrador, J. M., and Hughson, R. L. (2001). Inspiratory CO2 increases orthostatic tolerance during repeated tilt. Aviat. Space Environ. Med. 72, 985-991.

Boehm, K. E., Kip, K. T., Grubb, B. P., and Kosinski, D. J. (1997). Neurocardiogenic syncope: response to hormonal therapy. Pediatrics 99, 623-625.

Brainard, G. C., Petterborg, L. J., Richardson, B. A., and Reiter, R. J. (1982). Pineal melatonin in syrian hamsters: circadian and seasonal rhythms in animals maintained under laboratory and natural conditions. Neuroendocrinology 35, 342-348. doi: 10.1159/000123405

Braune, S., Wrocklage, C., Schulte-Monting, J., Schnitzer, R., Lucking, C. H., Schulte-Mönting, J., et al. (1999). Diagnosis of tachycardia syndromes associated with orthostatic symptoms. Clin. Auton. Res. 9, 97-101. doi: 10.1007/ bf02311766

Brignole, M. (2005). Neurally-mediated syncope. Ital. Heart J. 6, 249-255.

Brignole, M., Menozzi, C., Del Rosso, A., Costa, S., Gaggioli, G., Bottoni, N., et al. (2000). New classification of haemodynamics of vasovagal syncope: beyond the VASIS classification. Analysis of the pre-syncopal phase of the tilt test without and with nitroglycerin challenge. Vasovagal syncope international study. Europace 2, 66-76. doi: 10.1053/eupc.1999.0064

Brown, C. M., and Hainsworth, R. (1999). Assessment of capillary fluid shifts during orthostatic stress in normal subjects and subjects with orthostatic intolerance. Clin. Auton. Res. 9, 69-73. doi: 10.1007/bf02311762

Brown, C. M., and Hainsworth, R. (2000). Forearm vascular responses during orthostatic stress in control subjects and patients with posturally related syncope. Clin. Auton. Res. 10, 57-61. doi: 10.1007/bf02279892

Brunt, V. E., Miner, J. A., Kaplan, P. F., Halliwill, J. R., Strycker, L. A., and Minson, C. T. (2013). Short-term administration of progesterone and estradiol independently alter carotid-vasomotor, but not carotid-cardiac, baroreflex function in young women. Am. J. Physiol. Heart Circ. Physiol. 305, H1041-H1049. doi: 10.1152/ajpheart.00194.2013

Brunt, V. E., Miner, J. A., Meendering, J. R., Kaplan, P. F., and Minson, C. T. (2011). $17 \beta$-estradiol and progesterone independently augment cutaneous thermal hyperemia but not reactive hyperemia. Microcirculation 18, 347-355. doi: 10.1111/j.1549-8719.2011.00095.x

Burger, H. G., McLachlan, R. I., Bangah, M., Quigg, H., Findlay, J. K., Robertson, D. M., et al. (1988). Serum inhibin concentrations rise throughout normal male and female puberty. Obstet. Gynecol. Surv. 44, 379-380. doi: 10.1097/00006254198905000-00024

Bush, V. E., Wight, V. L., Brown, C. M., and Hainsworth, R. (2000). Vascular responses to orthostatic stress in patients with postural tachycardia syndrome (POTS), in patients with low orthostatic tolerance, and in asymptomatic controls. Clin. Auton. Res. 10, 279-284. doi: 10.1007/bf02281110

Büssemaker, E., Popp, R., Fisslthaler, B., Larson, C. M., and Fleming, I. (2003). Hyperthyroidism enhances endothelium-dependent relaxation in the rat renal artery. Cardiovasc. Res. 59, 181-188. doi: 10.1016/s0008-6363(03)00326-2

Carapetian, S., Siedlarz, M., Jackson, S., and Perlmuter, L. C. (2008). Orthostatic blood pressure regulation predicts classroom effort in children. Int. J. Psychophysiol. 68, 70-74. doi: 10.1016/j.ijpsycho.2008.01.004

Carey, B. J., Eames, P. J., Panerai, R. B., and Potter, J. F. (2001). Carbon dioxide, critical closing pressure and cerebral haemodynamics prior to vasovagal syncope in humans. Clin. Sci. 101, 351-358. doi: 10.1042/cs101 0351

Chen, C. Q., Fichna, J., Bashashati, M., Li, Y. Y., and Storr, M. (2011). Distribution, function and physiological role of melatonin in the lower gut. World J. Gastroenterol. 17, 3888-3898. doi: 10.3748/wjg.v17.i34.3888

Cheung, C. C., Thornton, J. E., Nurani, S. D., Clifton, D. K., and Steiner, R. A. (2001). A reassessment of leptin's role in triggering the onset of puberty in the rat and mouse. Neuroendocrinology 74, 12-21. doi: 10.1159/000054666
Claydon, V. E., and Hainsworth, R. (2003). Cerebral autoregulation during orthostatic stress in healthy controls and in patients with posturally related syncope. Clin. Auton. Res. 13, 321-329. doi: 10.1007/s10286-003-0120-8

Claydon, V. E., Norcliffe, L. J., Moore, J. P., Rivera-Ch, M., Leon-Velarde, F., Appenzeller, O., et al. (2004). Orthostatic tolerance and blood volumes in Andean high altitude dwellers. Exp. Physiol. 89, 565-571. doi: 10.1113/ expphysiol.2004.027698

Clemans, K. H., DeRose, L. M., Graber, J. A., and Brooks-Gunn, J. (2010). “Gender in adolescence: applying a person-in-context approach to gender identity and roles," in Handbook of Gender Research in Psychology: Volume 1: Gender Research in General and Experimental Psychology, eds J. C. Chrisler, and D. R. McCreary, (New York, NY: Springer), 527-559.

Conti, E., Carrozza, C., Capoluongo, E., Volpe, M., Crea, F., Zuppi, C., et al. (2004). Insulin-like growth factor-1 as a vascular protective factor. Circulation 110, 2260-2265. doi: 10.1161/01.cir.0000144309.87183.fb

Cooper, V. L., and Hainsworth, R. (2002). Effects of head-up tilting on baroreceptor control in subjects with different tolerances to orthostatic stress. Clin. Sci. 103, 221-226. doi: 10.1042/cs1030221

Cooper, V. L., and Hainsworth, R. (2008). Head-up sleeping improves orthostatic tolerance in patients with syncope. Clin. Auton. Res. 18, 318-324. doi: 10.1007/ s10286-008-0494-8

Crowley, S. J., Acebo, C., and Carskadon, M. A. (2012). Human puberty: salivary melatonin profiles in constant conditions. Dev. Psychobiol. 54, 468-473. doi: 10.1002/dev.20605

Cunningham, M. J., Clifton, D. K., and Steiner, R. A. (1999). Leptin's actions on the reproductive axis: perspectives and mechanisms. Biol. Reprod. 60, 216-222. doi: 10.1095/biolreprod60.2.216

Da, S. R., and da Silva, R. M. F. L. (2014). Syncope: epidemiology, etiology, and prognosis. Front. Physiol. 5:471. doi: 10.3389/fphys.2014.00471

Daffertshofer, M., Diehl, R. R., Ziems, G. U., and Hennerici, M. (1991). Orthostatic changes of cerebral blood flow velocity in patients with autonomic dysfunction. J. Neurol. Sci. 104, 32-38. doi: 10.1016/0022-510x(91)90212-p

de Jong-de Vos van Steenwijk, C. C., Wieling, W., Johannes, J. M., Harms, M. P., Kuis, W., and Wesseling, K. H. (1995). Incidence and hemodynamic characteristics of near-fainting in healthy 6- to 16-year old subjects. J. Am. Coll. Cardiol. 25, 1615-1621. doi: 10.1016/0735-1097(95)0 0056-a

Deda, L., Sochett, E. B., and Mahmud, F. H. (2015). Physiological changes in blood pressure impact peripheral endothelial function during adolescence. Cardiol. Young 25, 777-779. doi: 10.1017/S1047951114001024

Del Río, B., Garćia Pedrero, J. M., Martínez-Campa, C., Zuazua, P., Lazo, P. S., and Ramos, S. (2004). Melatonin, an endogenous-specific inhibitor of estrogen receptor $\alpha$ via calmodulin. J. Biol. Chem. 279, 38294-38302. doi: 10.1074/jbc. m403140200

Dhokalia, A., Parsons, D. J., and Anderson, D. E. (1998). Resting end-tidal CO2 association with age, gender, and personality. Psychosom. Med. 60, 33-37. doi: 10.1097/00006842-199801000-00007

Dossus, L., Kvaskoff, M., Bijon, A., Engel, P., Verdebout, J., Fervers, B., et al. (2013). Latitude and ultraviolet radiation dose in the birthplace in relation to menarcheal age in a large cohort of french women. Int. J. Epidemiol. 42, 590-600. doi: 10.1093/ije/dyt007

Dous, G. V., Grodman, R., Mornan, A., Otterbeck, P., and Grigos, A. (2014). Menopausal hormone treatment in postmenopausal women: risks and benefits. South. Med. J. 107, 689-695. doi: 10.14423/SMJ.0000000000000192

Driscoll, D. J., Jacobsen, S. J., Porter, C. J., and Wollan, P. C. (1997). Syncope in children and adolescents. J. Am. Coll. Cardiol. 29, 1039-1045.

Dunger, D. B., Perkins, J. A., Jowett, T. P., Edwards, P. R., Cox, L. A., Preece, M. A., et al. (1990). A longitudinal study of total and free thyroid hormones and thyroxine binding globulin during normal puberty. Acta Endocrinol. 123, 305-310. doi: 10.1530/acta.0.1230305

El-Sayed, H., Hainsworth, R., Sayed, H., and Hainsworth, R. (1995). El Relationship between plasma volume, carotid baroreceptor sensitivity and orthostatic tolerance. Clin. Sci. 88, 463-470. doi: 10.1042/cs0880463

El-Sayed, H., and Hainsworth, R. (1996). Salt supplement increases plasma volume and orthostatic tolerance in patients with unexplained syncope. Hear 75, 134-140. doi: 10.1136/hrt.75.2.134

Elmlinger, M. W., Kühnel, W., Lambrecht, H. G., and Ranke, M. B. (2001). Reference intervals from birth to adulthood for serum thyroxine (T4), 
triiodothyronine (T3), free T3, free T4, thyroxine binding globulin (TBG) and thyrotropin (TSH). Clin. Chem. Lab. Med. 39, 973-979.

Etienne, M., and Weimer, L. H. (2006). Immune-mediated autonomic neuropathies. Curr. Neurol. Neurosci. Rep. 6, 57-64. doi: 10.1007/s11910-9960010-2

Forbes, E. E., and Dahl, R. E. (2010). Pubertal development and behavior: hormonal activation of social and motivational tendencies. Brain Cogn. 72, 66-72. doi: 10.1016/j.bandc.2009.10.007

Fu, Q., Vangundy, T. B., Galbreath, M. M., Shibata, S., Jain, M., Hastings, J. L., et al. (2010). Cardiac origins of the postural orthostatic tachycardia syndrome. J. Am. Coll. Cardiol. 55, 2858-2868. doi: 10.1016/j.jacc.2010.02.043

Furlan, R., Jacob, G., Snell, M., Robertson, D., Porta, A., Harris, P., et al. (1998). Chronic orthostatic intolerance: a disorder with discordant cardiac and vascular sympathetic control. Circulation 98, 2154-2159. doi: 10.1161/01.cir.98.20.2154

Ganzeboom, K. S., Mairuhu, G., Reitsma, J. B., Linzer, M., Wieling, W., and van Dijk, N. (2006). Lifetime cumulative incidence of syncope in the general population: a study of 549 Dutch subjects aged 35-60 years. J. Cardiovasc. Electrophysiol. 17, 1172-1176. doi: 10.1111/j.1540-8167.2006.00595.x

Gill, S., Sharpless, J. L., Rado, K., and Hall, J. E. (2002). Evidence that GnRH decreases with gonadal steroid feedback but increases with age in postmenopausal women. J. Clin. Endocrinol. Metab. 8, 2290-2296. doi: 10.1210/ jc.87.5.2290

Gisolf, J., Wilders, R., Immink, R. V., van Lieshout, J. J., and Karemaker, J. M. (2004). Tidal volume, cardiac output and functional residual capacity determine end-tidal CO2 transient during standing up in humans. J. Physiol. 554(Pt 2), 579-590. doi: 10.1113/jphysiol.2003.056895

Grubb, B. P., Gerard, G., Roush, K., Temesy-Armos, P., Montford, P., Elliott, L., et al. (1991). Cerebral vasoconstriction during head-upright tilt-induced vasovagal syncope. A paradoxic and unexpected response. Circulation 84, 1157-1164. doi: 10.1161/01.cir.84.3.1157

Gulli, G., Cooper, V. L., Claydon, V. E., and Hainsworth, R. (2005a). Prolonged latency in the baroreflex mediated vascular resistance response in subjects with postural related syncope. Clin. Auton. Res. 15, 207-212. doi: 10.1007/s10286005-0273-8

Gulli, G., Claydon, V. E., Cooper, V. L., and Hainsworth, R. (2005b). R-R intervalblood pressure interaction in subjects with different tolerances to orthostatic stress. Exp. Physiol. 90, 367-375. doi: 10.1113/expphysiol.2004.029496

Gulli, G., Wight, V. L., Hainsworth, R., and Cevese, A. (2001). Spectral and crossspectral autoregressive analysis of cardiovascular variables in subjects with different degrees of orthostatic tolerance. Clin. Auton. Res. 11, 19-27. doi: $10.1007 /$ bf02317798

Guven, B., Oner, T., Tavli, V., Yilmazer, M. M., Demirpence, S., and Mese, T. (2013). Low iron storage in children with tilt positive neurally mediated syncope. World J. Pediatr. 9, 146-151. doi: 10.1007/s12519-012-0396-7

Hainsworth, R. (2004). Pathophysiology of syncope. Clin. Auton. Res. 14(Suppl. 1), $18-24$.

Hainsworth, R., Claydon, V. E., Bannister, R., and Mathias, C. (2012). "Syncope and fainting," in Autonomic Failure, 5th Edn, eds R. Bannister, and C. Mathias, (Oxford: Oxford University Press).

Hall, J. E., and Guyton, A. C. (2011). Guyton and Hall Textbook of Medical Physiology, 12th Edn. Amsterdam: Elsevier.

Hoeldtke, R. D., Horvath, G. G., and Bryner, K. D. (1995). Treatment of orthostatic tachycardia with erythropoietin. Am. J. Med. 99, 525-529. doi: 10.1016/s00029343(99)80230-7

Ishikawa, T., Chijiwa, T., Hagiwara, M., Mamiya, S., and Hidaka, H. (1989). Thyroid hormones directly interact with vascular smooth muscle strips. Mol. Pharmacol. 35, 760-765.

Itoh, Y., Suzuki, Y., Yamamoto, T., Kojima, K., Murakami, I., and Suzumori, N. (2006). Increase in serum concentrations of inhibin in early onset pre-eclampsia with intrauterine growth restriction. J. Obstet. Gynaecol. Res. 32, 80-85. doi: 10.1111/j.1447-0756.2006.00355.x

Jacob, G., Robertson, D., Mosqueda-Garcia, R., Ertl, A. C., Robertson, R. M., and Biaggioni, I. (1997). Hypovolemia in syncope and orthostatic intolerance role of the renin-angiotensin system. Am. J. Med. 103, 128-133. doi: 10.1016/s00029343(97)00133-2

Jarjour, I. T., and Jarjour, L. K. (2013). Low iron storage and mild anemia in postural tachycardia syndrome in adolescents. Clin. Auton. Res. 23, 175-179. doi: $10.1007 / \mathrm{s} 10286-013-0198-6$
Jørgensen, J. O., Møller, J., Laursen, T., Orskov, H., Christiansen, J. S., and Weeke, J. (1994). Growth hormone administration stimulates energy expenditure and extrathyroidal conversion of thyroxine to triiodothyronine in a dose-dependent manner and suppresses circadian thyrotrophin levels: studies in GH-deficient adults. Clin. Endocrinol. 41, 609-614. doi: 10.1111/j.1365-2265.1994.tb01826.x

Kanjwal, K., and Calkins, H. (2015). Syncope in children and adolescents. Cardiol. Clin. 33, 397-409. doi: 10.1016/j.ccl.2015.04.008

Kelsey, M. M., and Zeitler, P. S. (2016). Insulin resistance of puberty. Curr. Diab. 16:64. doi: 10.1007/s11892-016-0751-5

Kenny, R. A., Fillit, H. M., Rockwood, K., and Woodhouse, K. (2010). "Syncope," in Brocklehurst's Textbook of Geriatric Medicine and Gerontology, 7th Edn, eds H. M. Fillit, K. Rockwood, and K. Woodhouse, (Philadelphia: Saunders), 338-347.

Kitay, J. I. (1954). Pineal lesions and precocious puberty: a review. J. Clin. Endocrinol. Metab. 14, 622-625. doi: 10.1210/jcem-14-6-622

Kizilbash, S. J., Ahrens, S. P., Bruce, B. K., Chelimsky, G., Driscoll, S. W., HarbeckWeber, C., et al. (2014). Adolescent fatigue, POTS, and recovery: A guide for clinicians. Curr. Probl. Pediatr. Adolesc. Health Care 44, 108-133. doi: 10.1016/ j.cppeds.2013.12.014

Kolarov, N., Cerni, M., and Jović, B. (2005). Correlation of age at menarche of mothers and daughters in Backa Palanka. Med. Pregl. 58, 208-210. doi: 10.2298/ mpns0504208k

Kurbaan, A. S., Franzén, A. C., Bowker, T. J., Williams, T. R., Kaddoura, S., Petersen, M. E., et al. (1999). Usefulness of tilt test-induced patterns of heart rate and blood pressure using a two-stage protocol with glyceryl trinitrate provocation in patients with syncope of unknown origin. Am. J. Cardiol. 84, 665-670. doi: 10.1016/s0002-9149(99)00413-0

Lagi, A., Cencetti, S., Corsoni, V., Georgiadis, D., and Bacalli, S. (2001). Cerebral vasoconstriction in vasovagal syncope: any link with symptoms? A transcranial doppler study. Circulation 104, 2694-2698. doi: 10.1161/hc6172.09 9397

Lagi, A., Rossi, A., Sorelli, P., Cartei, A., and Cencetti, S. (2003). Plasma volume and hematocrit changes in recurrent fainters. Clin. Auton. Res. 13, 439-442.

Laranjo, S., Tavares, C., Oliveira, M., Trigo, C., Pinto, F., and Rocha, I. (2015). An insight into the autonomic and haemodynamic mechanisms underlying reflex syncope in children and adolescents: a multiparametric analysis. Cardiol. Young 25, 647-654. doi: 10.1017/S1047951114000511

Larson, R., Csikszentmihalyi, M., and Graef, R. (1980). Mood variability and the psychosocial adjustment of adolescents. J. Youth Adolesc. 9, 469-490. doi: 10. 1007/BF02089885

Lasiuk, G. C., and Hegadoren, K. M. (2007). The effects of estradiol on central serotonergic systems and its relationship to mood in women. Biol. Res. Nurs. 9, 147-160. doi: 10.1177/1099800407305600

Lee, D. Y., Kim, E., and Choi, M. H. (2015). Technical and clinical aspects of cortisol as a biochemical marker of chronic stress. BMB Rep. 48, 209-216. doi: 10.5483/bmbrep.2015.48.4.275

Li, J., Zhang, Q., Liao, Y., Zhang, C., Hao, H., and Du, J. (2015). The value of acetylcholine receptor antibody in children with postural tachycardia syndrome. Pediatr. Cardiol. 36, 165-170. doi: 10.1007/s00246-014-0981-8

Limonta, P., Marelli, M. M., Moretti, R., Marzagalli, M., Fontana, F., and Maggi, R. (2018). GnRH in the human female reproductive axis. Vitam. Horm. 107, 27-66. doi: 10.1016/bs.vh.2018.01.003

Linzer, M., Pontinen, M., Gold, D. T., Divine, G. W., Felder, A., and Blair Brooks, W. (1991). Impairment of physical and psychosocial function in recurrent syncope. J. Clin. Epidemiol. 44, 1037-1043. doi: 10.1016/0895-4356(91)90005-t

Low, P., Sandroni, P., Joyner, M., and Shen, W. K. (2009). Postural orthostatic tachycardia syndrome (POTS). J. Cardiovasc. Electrophysiol. 20, 352-358.

Low, P. A. (2014). "Postural orthostatic tachycardia syndrome (POTS)," in Encyclopedia of the Neurological Sciences, eds M. J. Aminoff, and R. B. Daroff, (Amsterdam: Elsevier), 964-967. doi: 10.1016/b978-0-12-385157-4.00509-1

Low, P. A., Opfer-Gehrking, T. L., Textor, S. C., Benarroch, E. E., Shen, W. K., Schondorf, R., et al. (1995). Postural tachycardia syndrome (POTS). Neurology 45(4 Suppl. 5), S19-S25. doi: 10.1016/b978-0-12-385157-4.00509-1

Maranon, R., and Reckelhoff, J. F. (2013). Sex and gender differences in control of blood pressure. Clin. Sci. Lond. 125, 311-318. doi: 10.1042/CS20130140

Marshall, W. A., and Tanner, J. M. (1970). Variations in pattern of pubertal changes in girls. Obstet. Gynecol. Surv. 25, 694-695. doi: 10.1097/00006254-19700700000018 
Massin, M. M., Bourguignont, A., Coremans, C., Comté, L., Lepage, P., and Gérard, P. (2004). Syncope in pediatric patients presenting to an emergency department. J. Pediatr. 145, 223-228. doi: 10.1016/j.jpeds.2004.01.048

Massin, M. M., Derkenne, B., Tallsund, M., Rocour-Brumioul, D., Ernould, C., Lebrethon, M. C., et al. (1999). Cardiac autonomic dysfunction in diabetic children. Diabetes 22, 1845-1850. doi: 10.2337/diacare.22.11. 1845

Mathias, C. J., Low, D. A., Iodice, V., Owens, A. P., Kirbis, M., and Grahame, R. (2012). Postural tachycardia syndrome-current experience and concepts. Nat. Rev. Neurol. 8, 22-34. doi: 10.1038/nrneurol.2011.187

Matteis, M., Troisi, E., Monaldo, B. C., Caltagirone, C., and Silvestrini, M. (1998). Age and sex differences in cerebral hemodynamics: a transcranial Doppler study. Stroke 29, 963-967. doi: 10.1161/01.str.29.5.963

McLeod, K. A. (2003). Syncope in childhood. Arch. Dis. Child. 88, 350-353. doi: 10.1136/adc.88.4.350

Medow, M. S., Stewart, J. M., Sanyal, S., Mumtaz, A., Sica, D., and Frishman, W. (2008). Pathophysiology. diagnosis, and treatment of orthostatic hypotension and vasovgal ayncope. Cardiol. Rev. 16, 4-20. doi: 10.1097/crd. 0b013e31815c8032

Meendering, J. R., Torgrimson, B. N., Houghton, B. L., Halliwill, J. R., and Minson, C. T. (2005). Menstrual cycle and sex affect hemodynamic responses to combined orthostatic and heat stress. Am. J. Physiol. Heart Circ. Physiol. 289, H631-H642.

Mendelsohn, M. E., and Karas, R. H. (1999). The protective effects of estrogen on the cardiovascular system. N. Engl. J. Med. 340, 1801-1811. doi: 10.1056/ nejm199906103402306

Messinis, I. E. (2006). From menarche to regular menstruation: endocrinological background. Ann. N. Y. Acad. Sci. 1092, 49-56. doi: 10.1196/annals.1365.004

Miner, J. A., Martini, E. R., Smith, M. M., Brunt, V. E., Kaplan, P. F., Halliwill, J. R., et al. (2011). Short-term oral progesterone administration antagonizes the effect of transdermal estradiol on endothelium-dependent vasodilation in young healthy women. Am. J. Physiol. Heart Circ. Physiol. 301, H1716-H1722. doi: 10.1152/ajpheart.00405.2011

Moak, J. P., Bailey, J. J., and Makhlouf, F. T. (2002). Simultaneous heart rate and blood pressure variability analysis. Insight into mechanisms underlying neurally mediated cardiac syncope in children. J. Am. Coll. Cardiol. 40, 1466-1474.

Moran, A., Jacobs, D. R., Steinberger, J., Cohen, P., Hong, C.-P., Prineas, R., et al. (2002). Association between the insulin resistance of puberty and the insulin-like growth factor-I/growth hormone axis. J. Clin. Endocrinol. Metab. 87, 4817-4820. doi: 10.1210/jc.2002-020517

Moran, A., Jacobs, D. R., Steinberger, J., Steffen, L. M., Pankow, J. S., Hong, C. P., et al. (2008). Changes in insulin resistance and cardiovascular risk during adolescence: establishment of differential risk in males and females. Circulation 117, 2361-2368. doi: 10.1161/CIRCULATIONAHA.107.704569

Mtinangi, B. L., and Hainsworth, R. (1998). Early effects of oral salt on plasma volume, orthostatic tolerance, and baroreceptor sensitivity in patients with syncope. Clin. Auton. Res. 8, 231-235. doi: 10.1007/bf02267786

Mtinangi, B. L., and Hainsworth, R. (1999). Effects of moderate exercise training on plasma volume, baroreceptor sensitivity and orthostatic tolerance in healthy subjects. Exp. Physiol. 84, 121-130. doi: 10.1111/j.1469-445x.1999.tb00077.x

Muniyappa, R., Montagnani, M., Koh, K. K., and Quon, M. J. (2007). Cardiovascular actions of insulin. Endocr, Rev. 28, 463-491. doi: 10.1210/er. 2007-0006

Murcia, G. J., Muñoz, H. A., Molina, C. A., García, J. M. F., Narbona, L. E., Murcia Garcia, J., et al. (2002). Puberty and melatonin. An. Esp. Pediatr. 57, 121-126.

Napoli, R., Guardasole, V., Angelini, V., D’Amico, F., Zarra, E., Matarazzo, M., et al. (2003). Acute effects of growth hormone on vascular function in human subjects. J. Clin. Endocrinol. Metab. 88, 2817-2820. doi: 10.1210/jc.2003030144

Nevo, O., Soustiel, J. F., and Thaler, I. (2007). Cerebral blood flow is increased during controlled ovarian stimulation. Am. J. Physiol. Circ. Physiol. 293, H3265-H3269.

Norcliffe, L. J., Bush, V. E., and Hainsworth, R. (2002). Patients with posturally related syncope have increased responsiveness of the cerebral circulation to carbon dioxide. Clin. Auton. Res. 12, 316.
Norcliffe-Kaufmann, L. J., Kaufmann, H., and Hainsworth, R. (2007). Enhanced vascular responses to hypocapnia in neurally mediated syncope. Ann. Neurol. 63, 288-294. doi: 10.1002/ana.21205

Nordkamp, L. R. O., Van, D. N., Ganzeboom, K. S., Reitsma, J. B., and Luitse, J. S. (2009). Syncope prevalence in the ED compared to general practice and population: a strong selection process. Am. J. Emerg. Med. 27, 271-279. doi: 10.1016/j.ajem.2008.02.022

Novak, V., Spies, J. M., Novak, P., McPhee, B. R., Rummans, T. A., and Low, P. A. (1998). Hypocapnia and cerebral hypoperfusion in orthostatic intolerance. Stroke 29, 1876-1881. doi: 10.1161/01.str.29.9.1876

O'Connor, K. A., Ferrell, R., Brindle, E., Trumble, B., Shofer, J., Holman, D. J., et al. (2009). Progesterone and ovulation across stages of the transition to menopause. Menopause 16, 1178-1187. doi: 10.1097/gme.0b013e3181aa192d

Palma, J. A., Norcliffe-Kaufmann, L., Fuente-Mora, C., Percival, L., Spalink, C. L., and Kaufmann, H. (2017). "Disorders of the autonomic nervous system: autonomic dysfunction in pediatric practice," in Swaiman's Pediatric Neurology: Principles and Practice, Sixth Edition, eds K. F. Swaiman, S. Ashwal, and M. I. Shevell, Amsterdam: Elsevier.

Palmeiro, C. R., Anand, R., Dardi, I. K., Balasubramaniyam, N., Schwarcz, M. D., and Weiss, I. A. (2012). Growth hormone and the cardiovascular system. Cardiol. Rev. 20, 197-207.

Preston, M. E., Jensen, D., Janssen, I., and Fisher, J. T. (2009). Effect of menopause on the chemical control of breathing and its relationship with acid-base status. Am. J. Physiol. Regul. Integr. Comp. Physiol. 296, R722-R727. doi: 10.1152/ ajpregu. 90865.2008

Protheroe, C. L., Ravensbergen, H. R., Inskip, J. A., and Claydon, V. E. (2013). Tilt Testing with combinedlLower body negative pressure: a "gold standard" for measuring orthostatic tolerance. J. Vis. Exp. 73:e4315. doi: 10.3791/4315

Purves-Tyson, T. D., Handelsman, D. J., Double, K. L., Owens, S. J., Bustamante, S., and Weickert, C. S. (2012). Testosterone regulation of sex steroid-related mRNAs and dopamine-related mRNAs in adolescent male rat substantia nigra. BMC Neurosci. 13:95. doi: 10.1371/journal.pone.0091151

Radtke, A., Lempert, T., von, B. M., Feldmann, M., Lezius, F., Neuhauser, H., et al. (2011). Prevalence and complications of orthostatic dizziness in the general population. Clin. Auton. Res. 21, 161-168. doi: 10.1007/s10286-010-0114-2

Raj, S. R. (2013). Postural tachycardia syndrome (POTS). Circulation 127, 2336-2342. doi: 10.1161/circulationaha.112.144501

Regensteiner, J. G., Woodard, W. D., Hagerman, D. D., Weil, J. V., Pickett, C. K., Bender, P. R., et al. (1989). Combined effects of female hormones and metabolic rate on ventilatory drives in women. J. Appl. Physiol. 66, 808-813.

Regidor, P. A. (2014). Progesterone in peri- and postmenopause: a review. Geburtshilfe Frauenheilkd. 74, 995-1002.

Rhie, Y. J. (2013). Kisspeptin/G protein-coupled receptor-54 system as an essential gatekeeper of pubertal development. Ann. Pediatr. Endocrinol. Metab. 18, 55-59. doi: 10.6065/apem.2013.18.2.55

Romero, C. J., Pine-Twaddell, E., Sima, D. I., Miller, R. S., He, L., Wondisford, F., et al. (2012). Insulin-Like Growth Factor 1 Mediates Negative Feedback to Somatotroph GH Expression via POU1F1/CREB Binding Protein Interactions. Mol. Cell Biol. 32, 4258-4269. doi: 10.1128/MCB.00171-12

Rose, M. S., Koshman, M. L., Spreng, S., and Sheldon, R. (2000). The relationship between health-related quality of life and frequency of spells in patients with syncope. J. Clin. Epidemiol. 53, 1209-1216. doi: 10.1016/s0895-4356(00) 00257-2

Rose, S. R., Municchi, G., Barnes, K. M., Kamp, G. A., Uriarte, M. M., Ross, J. L., et al. (1991). Spontaneous growth hormone secretion increases during puberty in normal girls and boys. J. Clin. Endocrinol. Metab. 73, 428-435. doi: 10.1210/jcem-73-2-428

Rosen, S. G., and Cryer, P. E. (1982). Postural tachycardia syndrome. Reversal of sympathetic hyperresponsiveness and clinical improvement during sodium loading. Am. J. Med. 72, 847-850.

Rossmanith, W. G., Laughlin, G. A., Mortola, J. F., and Yen, S. S. (1990). Secretory dynamics of oestradiol (E2) and progesterone (P4) during periods of relative pituitary LH quiescence in the midluteal phase of the menstrual cycle. Clin. Endocrinol. 32, 13-23. doi: 10.1111/j.1365-2265.1990.tb03745.x

Rozario, K. S., Lloyd, C., and Ryan, F. (2000). "GH and IGF-1 physiology in childhood," in Endotext, eds L. J. De Groot, G. Chrousos, K. Dungan, K. R. Feingold, and A. Grossman, (South Dartmouth, MA: MDText.com). 
Ruzieh, M., Batizy, L., Dasa, O., Oostra, C., and Grubb, B. (2017). The role of autoantibodies in the syndromes of orthostatic intolerance: a systematic review. Scand. Cardiovasc. J. 51, 243-247. doi: 10.1080/14017431.2017.135 5068

Rybaczyk, L. A., Bashaw, M. J., Pathak, D. R., Moody, S. M., Gilders, R. M., and Holzschu, D. L. (2005). An overlooked connection: serotonergic mediation of estrogen-related physiology and pathology. BMC Womens Health 5:12. doi: 10.1186/1472-6874-5-12

Saenger, P. (2003). Dose effects of growth hormone during puberty. Horm. Res. 60(Suppl. 1), 52-57. doi: 10.1159/000071226

Sakharova, A. A., Horowitz, J. F., Surya, S., Goldenberg, N., Harber, M. P., Symons, K., et al. (2008). Role of growth hormone in regulating lipolysis, proteolysis, and hepatic glucose production during fasting. J. Clin. Endocrinol. Metab. 93, 2755-2759. doi: 10.1210/jc.2008-0079

Sandroni, P., Opfer-Gehrking, T. L., McPhee, B. R., and Low, P. A. (1999). Postural tachycardia syndrome: clinical features and follow-up study. Mayo Clin. Proc. 74, 1106-1110. doi: 10.4065/74.11.1106

Satterthwaite, T. D., Shinohara, R. T., Wolf, D. H., Hopson, R. D., Elliott, M. A., Vandekar, S. N., et al. (2014). Impact of puberty on the evolution of cerebral perfusion during adolescence. Proc. Natl. Acad. Sci. U.S.A. 111, 8643-8648. doi: 10.1073/pnas.1400178111

Schroeder, C., Tank, J., Heusser, K., Diedrich, A., Luft, F. C., and Jordan, J. (2011). Physiological phenomenology of neurally-mediated syncope with management implications. PLoS One 6:e26489. doi: 10.1371/journal.pone.002 6489

Shahid, M. A., and Sharma, S. (2019). Physiology, Thyroid Hormone. Treasure Island, FL: StatPearls.

Shamma, F. N., Fayad, P., Brass, L., and Sarrel, P. (1992). Middle cerebral artery blood velocity during controlled ovarian hyperstimulation. Fertil. Steril. 57, 1022-1025. doi: 10.1016/s0015-0282(16)55020-1

Shankar, R. R., Eckert, G. J., Saha, C., Tu, W., and Pratt, J. H. (2005). The change in blood pressure during pubertal growth. J. Clin. Endocrinol. Metab. 90, 163-167. doi: 10.1210/jc.2004-0926

Shaw, B. H., Stiles, L. E., Bourne, K., Green, E. A., Shibao, C. A., Okamoto, L. E., et al. (2019) The face of postural tachycardia syndrome - insights from a large cross-sectional online community-based survey. J. Intern. Med. 286, 438-448. doi: 10.1111/joim. 12895

Shaw, N. D., Butler, J. P., Nemati, S., Kangarloo, T., Ghassemi, M., Malhotra, A., et al. (2015). Accumulated deep sleep is a powerful predictor of LH pulse onset in pubertal children. J. Clin. Endocrinol. Metab. 100, 1062-1070. doi: 10.1210/jc.2014-3563

Shaw, N. D., Histed, S. N., Srouji, S. S., Yang, J., Lee, H., and Hall, J. E. (2010). Estrogen negative feedback on gonadotropin secretion: evidence for a direct pituitary effect in women. J. Clin. Endocrinol. Metab. 95, 1955-1961. doi: 10. 1210/jc.2009-2108

Silman, R. E., Leone, R. M., Hooper, R. J., and Preece, M. A. (1979). Melatonin, the pineal gland and human puberty. Nature 282, 301-303. doi: 10.1038/2823 $01 \mathrm{a} 0$

Sinclair, D., Purves-Tyson, T. D., Allen, K. M., and Weickert, C. S. (2014). Impacts of stress and sex hormones on dopamine neurotransmission in the adolescent brain. Psychopharmacology 231, 1581-1599. doi: 10.1007/s00213-0133415-z

Singer, W., Sletten, D. M., Opfer-Gehrking, T. L., Brands, C. K., Fischer, P. R., and Low, P. A. (2012). Postural tachycardia in children and adolescents: what is abnormal? J. Pediatr. 160, 222-226. doi: 10.1016/j.jpeds.2011. 08.054

Slatkovska, L., Jensen, D., Davies, G. A. L., and Wolfe, L. A. (2006). Phasic menstrual cycle effects on the control of breathing in healthy women. Respir. Physiol. Neurobiol. 154, 379-388. doi: 10.1016/j.resp.2006.01.011

Sliwowska, J. H., Fergani, C., Gawałek, M., Skowronska, B., Fichna, P., and Lehman, M. N. (2014). Insulin: its role in the central control of reproduction. Physiol. Behav. 133, 197-206. doi: 10.1016/j.physbeh.2014.05.021

Smit, A. A. J., Halliwill, J. R., Low, P. A., and Wieling, W. (1999). Pathophysiological basis of orthostatic hypotension in autonomic failure. J. Physiol. 519, 1-10. doi: 10.1111/j.1469-7793.1999.0001o.x

Soliman, A., Sanctis, V. D., Elalaily, R., and Bedair, S. (2014). Advances in pubertal growth and factors influencing it: can we increase pubertal growth? Indian J. Endocrinol. Metab. 18, 53-62. doi: 10.4103/2230-8210.145075
Stewart, J. M. (2009). Postural tachycardia syndrome and reflex syncope: similarities and differences. J. Pediatr. 154, 481-485. doi: 10.1016/j.jpeds.2009. 01.004

Stewart, J. M., McLeod, K. J., Sanyal, S., Herzberg, G., and Montgomery, L. D. (2004). Relation of postural vasovagal syncope to splanchnic hypervolemia in adolescents. Circulation 110, 2575-2581. doi: 10.1161/01.cir.0000145543. 88293.21

Stewart, J. M., Medow, M. S., Cherniack, N. S., and Natelson, B. H. (2006). Postural hypocapnic hyperventilation is associated with enhanced peripheral vasoconstriction in postural tachycardia syndrome with normal supine blood flow. Am. J. Physiol. Heart Circ. Physiol. 291, H904-H913.

Stroud, L. R., Papandonatos, G. D., Williamson, D. E., and Dahl, R. E. (2011). Sex differences in cortisol response to corticotropin releasing hormone challenge over puberty: pittsburgh pediatric neurobehavioral studies. Psychoneuroendocrinology 36, 1226-1238. doi: 10.1016/j.psyneuen.2011. 02.017

Sung, R. Y., Du, Z. D., Yu, C. W., Yam, M. C., and Fok, T. F. (2000). Cerebral blood flow during vasovagal syncope induced by active standing or head up tilt. Arch. Dis. Child. 82, 154-158. doi: 10.1136/adc.82.2.154

Swerdloff, R. S., and Odell, W. D. (1975). Hormonal mechanisms in the onset of puberty. Postgrad. Med. J. 51, 200-208. doi: 10.1136/pgmj.51.594.200

Tanaka, H., Borres, M., Thulesius, O., Tamai, H., Ericson, M. O., and Lindblad, L. E. (2000). Blood pressure and cardiovascular autonomic function in healthy children and adolescents. J. Pediatr. 137, 63-67. doi: 10.1067/mpd.2000.108098

Teixeira, R. R., Díaz, M. M., Santos, T. V., da, S., Bernardes, J. T. M., Peixoto, L. G., et al. (2015). Chronic stress induces a hyporeactivity of the autonomic nervous system in response to acute mental stressor and impairs cognitive performance in business executives. PLoS One 10:e0119025. doi: 10.1371/ journal.pone.0119025

Theodorakis, G. N., Markianos, M., Livanis, E. G., Zarvalis, E., Flevari, P., and Kremastinos, D. T. (1998). Central serotonergic responsiveness in neurocardiogenic syncope: a clomipramine test challenge. Circulation 98, 27242730. doi: 10.1161/01.cir.98.24.2724

Thomas, H. M. (1957). Effect of thyroid hormone on circulation. J. Am. Med. Assoc. $163,337-341$.

Thomson, H. L., Wright, K., and Frenneaux, M. (1997). Baroreflex sensitivity in patients with vasovagal syncope. Circulation 95, 395-400. doi: 10.1161/01.cir. 95.2.395

Vaddadi, G., Esler, M. D., Dawood, T., and Lambert, E. (2010). Persistence of muscle sympathetic nerve activity during vasovagal syncope. Eur. Heart J. 31, 2027-2033. doi: 10.1093/eurheartj/ehq071

Van De Wielle, R. V., and Michels, N. (2017). Longitudinal associations of leptin and adiponectin with heart rate variability in children. Front. Physiol. 8:498. doi: 10.3389/fphys.2017.00498

Van Dijk, N., Sprangers, M. A., Boer, K. R., Colman, N., Wieling, W., and Linzer, M. (2007). Quality of life within one year following presentation after transient loss of consciousness. Am. J. Cardiol. 100, 672-676. doi: 10.1016/j.amjcard.2007. 03.085

van Lieshout, J. J., Wieling, W., Karemaker, J. M., and Eckberg, D. L. (1991). The vasovagal response. Clin. Sci. Lond. 81, 575-586.

Vehkavaara, S., Westerbacka, J., Hakala-Ala-Pietilä, T., Virkamäki, A., Hovatta, O., and Yki-Järvinen, H. (2000). Effect of estrogen replacement therapy on insulin sensitivity of glucose metabolism and preresistance and resistance vessel function in healthy postmenopausal women. J. Clin. Endocrinol. Metab. 85, 4663-4670. doi: 10.1210/jc.85.12.4663

Viner, R., and Christie, D. (2005). Fatigue and somatic symptoms. BMJ 330, 1012-1015. doi: 10.1136/bmj.330.7498.1012

Wagoner, A. L., Shaltout, H. A., Fortunato, J. E., and Diz, D. I. (2016). Distinct neurohumoral biomarker profiles in children with hemodynamically defined orthostatic intolerance may predict treatment options. Am. J. Physiol. Heart Circ. Physiol. 310, H416-H425. doi: 10.1152/ajpheart.00583.2015

Walsh, C. A. (2001). Syncope and sudden death in the adolescent. Adolesc. Med. $12,105-132$.

Wennink, J. M., Delemarre-van de Waal, H. A., Schoemaker, R., Schoemaker, H., and Schoemaker, J. (1990). Luteinizing hormone and follicle stimulating hormone secretion patterns in girls throughout puberty measured using highly sensitive immunoradiometric assays. Clin. Endocrinol. 33, 333-344. doi: 10. 1111/j.1365-2265.1990.tb00498.x 
Wheeler, M. D. (1991). Physical changes of puberty. Endocrinol. Metab. Clin. North Am. 20, 1-14.

White, D. P., Douglas, N. J., Pickett, C. K., Weil, J. V., and Zwillich, C. W. (1983). Sexual influence on the control of breathing. J. Appl. Physiol. 54, 874-879. doi: 10.1152/jappl.1983.54.4.874

Wieling, W., Ganzeboom, K. S., and Saul, J. P. (2004). Reflex syncope in children and adolescents. Heart 90, 1094-1100. doi: 10.1136/hrt.2003.022996

Wieling, W., Smit, A. A., de Jong-de Vos van Steenwijk, C. C., van Lieshout, J. J., and Karemaker, J. M. (1997). Pathophysiological mechanisms underlying vasovagal syncope in young subjects. Pacing Clin. Electrophysiol. 20(8 Pt 2), 2034-2038. doi: 10.1111/j.1540-8159.1997.tb03622.x

Wilson, T. E., Cui, J., Zhang, R., and Crandall, C. G. (2006). Heat stress reduces cerebral blood velocity and markedly impairs orthostatic tolerance in humans. Am. J. Physiol. Regul. Integr. Comp. Physiol. 291, R1443-R1448.

Winter, J. S. D., and Faiman, C. (1973). The development of cyclic pituitarygonadal function in adolescent females. J. Clin. Endocrinol. Metab. 37, 714-718. doi: 10.1210/jcem-37-5-714
Zhao, J., Han, Z., Zhang, X., Du, S., Liu, A. D., Holmberg, L., et al. (2015). A crosssectional study on upright heart rate and BP changing characteristics: basic data for establishing diagnosis of postural orthostatic tachycardia syndrome and orthostatic hypertension. BMJ Open 5:95. doi: 10.1136/bmjopen-2014-0 07356

Conflict of Interest: The authors declare that the research was conducted in the absence of any commercial or financial relationships that could be construed as a potential conflict of interest.

Copyright (0) 2019 Coupal, Heeney, Hockin, Ronsley, Armstrong, Sanatani and Claydon. This is an open-access article distributed under the terms of the Creative Commons Attribution License (CC BY). The use, distribution or reproduction in other forums is permitted, provided the original author(s) and the copyright owner(s) are credited and that the original publication in this journal is cited, in accordance with accepted academic practice. No use, distribution or reproduction is permitted which does not comply with these terms. 